\section{EL MOTU PROPRIO DEL PAPA FRANCISCO QUE DEROGÓ LA CONSULTA OBLIGATORIA PARA LAS SENTENCIAS DE NULIDAD DEL MATRIMONIO CATÓLICO*}

\author{
THE MOTU PROPRIO OF POPE FRANCIS \\ WHO ABOLISHED THE MANDATORY \\ CONSULTATION FOR CATHOLIC \\ MARRIAGE ANNULMENTS
}

O MOTU PRÓPRIO DO PAPA FRANCISCO QUE REVOGOU A CONSULTA OBRIGATÓRIA PARA OS JULGAMENTOS DE NULIDADE DO CASAMENTO CATÓLICO
Vilma S. Moreno Díaz ${ }^{a}$ vismodi@yahoo.esm Fecha de recepción: 15 de enero de 2016 Fecha de revisión: 10 de febrero de 2016 Fecha de aceptación: 24 de abril de 2016

\title{
RESUMEN
}

El Papa Francisco, en su calidad de jerarca y representante de la Iglesia Católica y en ejercicio de su potestad de régimen legislativa derogó la Consulta obligatoria para aquellas sentencias de primera instancia que declararen la nulidad del matrimonio católico. Nulidades que, también en virtud de la potestad de régimen jurisdiccional, son de competencia exclusiva de los Tribunales Eclesiásticos. Dicha consulta también se establece en Colombia para ciertos procesos, y en algunos casos también ya fue derogada.

\section{PALABRAS CLAVES}

Iglesia, Motu proprio, Potestad de régimen, Matrimonio, Sentencia de nulidad, Consulta obligatoria, Proceso, celeridad, economía procesal.

\footnotetext{
* Artículo producto de investigación realizada en el Centro de Investigaciones Francisco de Vitoria, dentro del programa de Doctorado en Derecho de la Universidad Santo Tomas.

a. Abogada egresada de la Universidad Santo Tomás, Especialista en Derecho de Familia de la misma universidad, Magister en Derecho Canónico de la Universidad Pontificia Comillas de Madrid (España), Doctora en Derecho Canónico de las Universidades Pontificia Comillas y Javeriana. Docente universitaria en el área de Familia y Sucesiones desde el año 2.000, Abogada litigante ante los Tribunales Eclesiásticos y ante la jurisdicción de familia. Tutora del Doctorado de Derecho de la Universidad Santo Tomás y esta investigación se enmarca dentro del grupo de investigación del Doctorado.
}

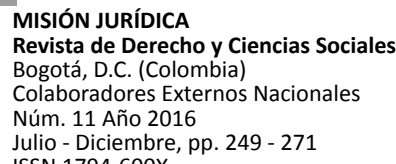




\section{ABSTRACT}

Pope Francis, as the head and representative of the Catholic Church and in exercise of his power on the legislative regime abolished the compulsory consultation to those judgments at first instance, which declare the annulment of a Catholic marriage. Annulments that also under the power of a jurisdictional regime, are of exclusive competence of the courts of Ecclesiastical power. Such consultation is also set in Colombia for certain processes, and in some cases has also been repealed.

\section{KEY WORDS}

Church, motu proprio, authority of the regime, marriage, decree of nullity, mandatory consultation, process, celerity, procedural economy.

\section{RESUMO}

O Papa Francisco, na sua qualidade de chefe e representante da Igreja Católica e no exercício do seu poder de regime legislativo aboliu a consulta obrigatória para os primeiros julgamentos de instância que declararem a nulidade do casamento católico. Anulações que, também sob a autoridade de um sistema judicial, são da competência exclusiva dos tribunais eclesiásticos. Essa consulta também é definida na Colômbia para determinados processos, e em alguns casos já tenha sido revogada.

\section{PALAVRAS-CHAVE}

Ig Igreja, Motu próprio, poder de regime, Casamento, sentença de nulidade, consulta obrigatória, Processo, velocidade, economia processual.

\section{INTRODUCCIÓN}

El Motu Proprio ${ }^{1}$ (Lombardia, 1975, 210 212), "Mitis Iudex Dominus Iesus" es una ley de la Iglesia católica de autoría papal, cuyo contenido modifica o perfecciona otra ley, que se convirtió en tema noticioso en los últimos días del 2015. Como consecuencia de la promulgación que hizo el Papa Francisco acerca del procedimiento que se adelanta en los Tribunales eclesiásticos, en aras de favorecer a los católicos para hacer más ágil ${ }^{3}$ el trámite de nulidad del matrimonio católico, eliminó la segunda instancia obligatoria en los procesos, dando lugar a que la primera sentencia quede ejecutoriada, si no hay objeción.

(...) I. Una sola sentencia en favor de la nulidad es ejecutiva.- Ha parecido oportuno, antes que nada, que no sea más requerida una doble decisión conforme a favor de la nulidad del matrimonio, para que las partes sean admitidas a nuevo matrimonio canónico, sino que sea suficiente la certeza moral alcanzada por el primer juez, a norma del derecho.

(...)

Art. 4 - De la sentencia, sus impugnaciones y su ejecución

Can. 1679. La sentencia que por primera vez ha declarado la nulidad del matrimonio, cumplidos los términos establecidos en los cánones 1630-1633, se hace ejecutiva.

Can. 1680 \& 1. Permanece íntegro el derecho de la parte que se considere perjudi-cada, así como del promotor de justicia y del defensor del vínculo, de interponer querella de nulidad o apelación contra la misma sentencia, según los cánones 1619-1640 (Francisco, 2015) subrayas fuera del original.

1. "El Romano Pontífice puede dictar leyes universales y particulares, y puede hacerlo en forma de Bula o Breve, como Constitución Apostólica o Letras dadas motu proprio".

2. "El Señor Jesús, Juez Clemente. Pastor de nuestras almas, encomendó al Apóstol Pedro y a sus sucesores, el poder de las llaves para llevar a cabo en la Iglesia la obra de justicia y de verdad; esta Potestad suprema e universal de atar y desatar aquí en la tierra afirma, corrobora y reivindica la de los Pastores de las Iglesias particulares, en virtud de la cual estos tienen el sagrado derecho, y ante el Señor el deber, de juzgar a sus propios súbditos..." Motu Proprio sobre la reforma del proceso canónico para las causas de declaración de nulidad del matrimonio en el Código de Derecho Canónico, Roma, 15 de Agosto de 2015.

3. En el Documento Preliminar al Sínodo - Relatio post disceptationem (Relación después de la discu-sión), en el numeral 43 se señaló: "Diversos Padres han subrayado la necesidad de hacer más accesibles y ágiles los procedimientos para el reconocimiento de casos de nulidad. Entre las propuestas han sido indica-das la superación de la necesidad de la doble sentencia conforme; la posibilidad de determinar una vía admi-nistrativa bajo la responsabilidad del obispo diocesano; un proceso sumario para realizar en los casos de nulidad notoria. Según propuestas autorizadas, se debe considerar la posibilidad de dar relevancia a la fe de los novios en orden a la validez del sacramento del matrimonio. Hay que destacar que en todos los casos se trata de establecer la verdad sobre la validez del vínculo».

4. El canon 1682 del Código de Derecho Canónico establecía "\& 1. La sentencia que declara por vez primera la nulidad de un matrimonio, junto con las apelaciones, si las hay, y demás actas del proceso, debe transmitirse de oficio al tribunal de apelación dentro del plazo de veinte días a partir de la publicación de la sentencia. ..." 
A raíz de la promulgación de esta modificación, muchos fieles y abogados se han cuestionado sobre los alcances de la jurisdicción y los procesos en el derecho canónico. Como se trata además del matrimonio como institución sacramental, es preciso advertir que para una mayor comprensión de tal innovación, este artículo se desarrolla teniendo en cuenta la particular naturaleza de la normatividad canónica. Por esto, resulta conveniente referirnos en primer lugar a los orígenes de la potestad eclesiástica de la iglesia, prerrogativa a partir de la cual el Papa Francisco hizo las modificaciones respecto de la Nulidad del matrimonio católico; en segundo término se establecerá una relación de los antecedentes concordatarios vigentes en Colombia, de acuerdo con los pronunciamientos de la Corte Constitucional respecto del Concordato de 1973 y la ley aprobatoria que reconoce la Potestad del Régimen eclesiástico en Colombia y la jurisprudencia, se continuará con una reseña de cómo fue incorporada en diferentes momentos la Consulta en el Derecho procesal Colombiano y se finaliza con la Consulta y segunda instancia en el proceso de nulidad del matrimonio católico, concluyendo con los argumentos expuestos en el Motu Proprio referentes a la modificación realizada en cuanto a los procesos de nulidad del matrimonio católico.

\section{METODOLOGÍA}

De acuerdo con Elgueta y Palma (2010) esta es una investigación documental, descriptiva, explicativa, de tipo teórico cualitativo (p. 125,137 y ss.) realizada me-diante un método históricodescriptivo (Hernández, Collado \& Baptista, 1992).

Se caracteriza por la búsqueda y recolección de datos, su análisis, relación e in-terpretación de las fuentes objeto de estudio. La dimensión histórica sirve de fun-damento para entender documentos, conceptos y normas de Derecho Canónico y Derecho Civil que establecen la Consulta como una alzada procesal de tipo obli-gatorio.

Este diseño metodológico (Tamayo y Tamayo, 1997) permitió recopilar la informa-ción necesaria para elaborar un Marco Conceptual que definió tres fases, a saber: (i) Fase Inicial: Revisión bibliográfica y jurisprudencial, para la construcción del Marco Conceptual. (ii) Fase de análisis: Estudio de la historia y evolución del concepto de Consulta. Realización de un paralelo entre la consulta en el Dere-cho Canónico y el Derecho Civil Colombiano. (iii) Fase de crítica y discusión: Análisis del Motu proprio del Papa en relación a la derogatoria a la Consulta obli-gatoria $\mathrm{y}$ las diferentes opiniones sobre el tema.

\section{DESARROLLO DE LA DISCUSIÓN}

\section{La potestad de régimen en la iglesia católica}

(...)Jesús les dijo: Yo he recibido todo poder en el cielo y en la tierra. Vayan, entonces, y hagan que todos los pueblos sean mis discípulos, bautizándolos en el nombre del Padre y del Hijo y del Espíritu Santo, y enseñándoles a cumplir todo lo que yo les he mandado. Y yo estoy con ustedes hasta el fin del mundo. (Mateo 28, 16-20 Biblia de Jerusalén) ${ }^{5}$.

El contenido del texto evangélico sirve de fundamento a la Teología, para resaltar cómo en las Sagradas Escrituras está explícito el poder de Dios, sus profetas y apóstoles en el mundo. En la Edad Media, - Siglos XII - XV - gracias a los aportes iniciales del monje y jurista italiano, Graciano ${ }^{6}$, se unifica y armonizan los Cánones expedidos en los siglos anteriores, y las Decretales ${ }^{7}$ de Gregorio IX que pasaron a formar parte del Corpus Iuris Canonici. Estos escritos, son fuentes del Derecho Canónico y en ellos se contempla la regulación jurídica de la potestad de la Iglesia, reconocida como diferente al - Corpus Iuris Civilis - de Justiniano en el Derecho Romano.

Esta primera distinción entre Derecho eclesiástico y Derecho Civil, va a ser el mecanismo para justificar algunos de los grandes cismas a lo largo de la historia de la Iglesia Católica ${ }^{8}$. El desconocimiento del poder terrenal de la Iglesia por Martin Lutero (1.483 - 1.546), es una muestra

5. "Yo seguía contemplando en las visiones de la noche: $Y$ he aquí que en las nubes del cielo venía como el Hijo del hombre. Se dirigió hacía el Anciano y fue llevado a su presencia. A él se le dio imperio, honor y reino, y todos los pueblos, naciones y lenguas le sirvieron. Su imperio es un imperio eterno, que nunca pasará, y su reino no será destruido jamás" (Daniel 7, 13 - 14).

6. Es en la universidad de Bolonia, donde se desarrolló la mayor parte de su estudio y trabajo de armonización de los cánones que fueran contrarios, a juicio de los historiadores entre los años 1140 y 1142.

7. Cartas en las que se comunican las decisiones de los Papas. Son el antecedente del Derecho Canónico y comprenden las escritas entre los siglos IV al XV. 
de ello, pues consideraba que "lo jurídico en la Iglesia es contrapuesto al dogma" (Gerosa, 1998, p.21). "Lutero insistió en la obediencia al poder civil, contribuyendo a reforzar el absolutismo monárquico y desautorizando movimientos populares inspirados en su doctrina” (LOA, 2015).

Similar situación es la que acompaña el caso de Enrique VIII (1491 - 1547), ante su particular interés por casarse con Ana Bolena, con quien esperaba tener un hijo varón. Ante la negativa de la Iglesia de conceder la nulidad de su matrimonio con la hija de los reyes Católicos - Catalina de Aragón -, decide desconocer la potestad espiritual del Papa Clemente Séptimo y con ella la de la Iglesia Católica, asumiendo así una de las formas de gobierno de los nuevos Estados de Europa occidental, el absolutismo. Como nuevo soberano de la naciente Iglesia Anglicana, conjugó el poder terrenal del Estado con el poder espiritual de la Iglesia.

El clérigo Thomas Cranmer, sostenía que no era preciso seguir el proceso de divorcio en Roma, sino que bastaba con que se obtuviese de algunos teólogos eminentes la certeza de la nulidad del primer matrimonio. El rey tan pronto oyó tales razonamien-tos los puso en práctica. Consultó a las Universidades de Oxford y Cambridge, que se manifestaron favorables a la causa real, e igual sucedió con otros seis centros docen-tes que fueron interrogados. Los resultados obtenidos se elevaron para su aprobación al Parlamento, que respondió reconociendo a Enrique, en 1531, como «Único Jefe Supremo de la lglesia» en Inglaterra. En 1533, Cranmer fue nombrado arzobispo de Canterbury, casando en secreto al rey con Ana Bolena, que ya esperaba un hijo. El 23 de abril declaró nulo el primer matrimonio y, a continuación, anunció la nueva boda. El 1 de junio coronó a Ana Bolena como reina de Inglaterra. El Parlamento aprobó el Acta de Apelaciones, prohibiendo a los tribunales eclesiásticos ingleses apelar a Roma, a lo que contestó el Papa excomulgando a Enrique el 23 marzo 1534 (Bernáldez, 2015).

En el siglo XVI, ante la consolidación de los Estados Nacionales, se conoce el Ius Publicum Ecclesiasticum (Gerosa, 1998, p.88) que hablaba de la juridicidad de la iglesia que tenía como lema

8. Dentro de las tesis que desconocen lo jurídico del Derecho canónico encontramos: El espiritualismo que rechaza la dimensión visible e institucional de la Iglesia (Lutero y Calvino); El regalismo que cuestionó la juridicidad del derecho Canónico porque cree que esta le pertenece solo al poder civil o estatal; El positivismo estatalista que reduce lo jurídico solo a lo positivo e identifica el Estado con el Derecho. que ésta era "societas perfecta supernaturalis" y el principio "ubi societas ibi ius"9 (Viladrich, 1975, p.52). Posición contraria la adoptada por los protestantes a raíz del movimiento de la Reforma, para quienes la iglesia sólo era una asociación que debía estar sometida a la jurisdicción del Estado.

(...) la iglesia por tanto debe ser definida como:(...) una Res pública sacra, independiente, distinta del Estado y reducible a una simple societas arbitraria, es decir, fundada sobre el libre contrato estipulado por sus miembros. Es más, en virtud de haber sido constituida por Cristo, la comunidad de los creyentes es una societas mecessaria y como tal, aunque no tenga territorio, posee un verdadero summum imperium, o sea, todos los poderes necesarios para la consecución de su propio fin: la salvación eterna de sus miembros (García, 2011, p.40).

1.1.- En el contexto de la Iglesia Católica, se encuentra el Estado del Vaticano y la Santa Sede ${ }^{10}$ que poseen una estructura legal y organización propia y cuenta por lo tanto en lo jurídico, con lo que se conoce canónicamente como "potestad de régimen"11.

Autores como Cenalmor \& Miras, (2010) expresan que:

Toda sociedad bien organizada, además de acoger en su ordenamiento aquellos derechos y deberes que delinean los ámbitos de libertad y responsabilidad de sus miembros, cuenta con un poder necesario -que ha de ejercerse según Derecho y en servicio a la sociedad- para tutelar esos derechos y exigir el cumplimiento de esos deberes. En efecto, cualquier comunidad humana necesita una autoridad que la rija y la mantenga unida, asegurando en cuanto sea posible el bien común de la sociedad.

Esto sucede también en la Iglesia in terris, con ciertas peculiaridades, ya que:

9. Sin realidad societaria, no hay derecho, sin Derecho tampoco hay sociedad. Se dan simultáneamente. El que la Iglesia tenga una dimensión social hace que tenga a su vez un Derecho propio.

10. Para asegurar a la Santa Sede un territorio e independencia en el ejercicio de su misión, surge con el Tratado de Letrán "El Estado del Vaticano", 1929.

11. A la potestad de régimen de la Iglesia solo están sometidos los bautizados en su seno, conforme a los cánones 96, 204 del Código de Derecho Canónico "... \&2- Esta Iglesia, constituida y ordenada como sociedad en este mundo, subsiste en la Iglesia católica, gobernada por el sucesor de Pedro y por los Obispos en comunión con él." 
El pueblo de Dios es una entidad institucional, cuya constitución y gobierno no depende de la libre iniciativa de sus miembros (como sucede en las actuales sociedades democráticas), sino lo dispuesto por su divino fundador (p.219).

Este poder sagrado particular del poder eclesiástico, tiene su razón de ser en el origen divino y sacramental, que junto con el principio jerárquico de la iglesia, es lo que, otorga la capacidad de "realizar funciones sagradas, como la de los sacramentos" (Cenalmor \& Miras, 2010, p. 221).

En cuanto al poder de gobernar el pueblo de Dios como sociedad y conducirlo hacia sus fines - la salvación - es lo que se conoce como "Potestad de régimen (del latin regere: regir), o de jurisdicción". A diferencia de la potestad sagrada de la que originariamente forma parte, y en la que radica y se sostiene-, la potestad de régimen es de índole netamente jurídico, e implica la facultad de emitir disposiciones, decisiones o mandatos, con eficacia jurídica reconocida por el ordenamiento para vincular a los fieles. "Actos propios de este tipo de potestad son, p.ej., promulgar una ley, conceder la dispensa de un impedimento, emitir un decreto de nombramiento o dictar una sentencia judicial (Cenalmor \& Miras, 2010, p. 221) ${ }^{12}$.

Este poder de gobernar a la iglesia como institución social y a sus fieles, recae en el romano Pontífice y los Obispos, quienes forman la jerarquía de jurisdicción. Es una potestad de régimen indivisible, pero en ella a juicio de los canonistas se puede distinguir: "Una función jurisdiccional, que se desarrolla aplicando a personas concretas y a casos determinados la norma contenida en la ley" (Tirapu \& López-Sidro, 2004, p. 99).

1.2.- En el Código de Derecho Canónico ${ }^{13}$ se regula dicha Potestad de régimen en los siguientes cánones:

12. ...La potestad de régimen no debe confundirse con la función de regir o munus regendi, que es un concepto más amplio: la función regia -de la que participan todos los fieles, "cada uno según su propia condición" (cf. C.204 No. 1)-incluye todas las actividades que contribuyen a ordenar la vida del Pueblo de Dios hacia la consecución del fin de la Iglesia (exhortaciones, consejos, ejemplo, testimonio, etc.), y no solo las disposiciones imperativas y jurídicamente vinculantes."

13. En este punto cabe precisar a quienes desconocen el derecho Canónico, que en la Iglesia Católica existen dos Códigos de Derecho Canónico, uno para la Iglesia de Occidente y otro para la Iglesia de Oriente. La de Occidente tuvo su primer código en 1917 y el que está vigente es de 1983, la Iglesia de Oriente tiene un código que la rige desde 1991. En este artículo nos referimos
Canon 129 § 1 . De la potestad de régimen, que existe en la Iglesia por institución divina, y que se llama también potestad de jurisdicción, son sujetos hábiles, conforme a la norma de las prescripciones del derecho, los sellados por el orden sagrado.

Canon $135 \S 1$. La potestad de régimen se divide en legislativa, ejecutiva y judicial.

$\S 2$. La potestad legislativa se ha de ejercer del modo prescrito por el derecho, y no puede delegarse válidamente aquella que tiene el legislador inferior a la autoridad suprema, a no ser que el derecho disponga explícitamente otra cosa; tampoco puede el legislador inferior dar válidamente una ley contraria al derecho de rango superior.

$\S 3$. La potestad judicial que tienen los jueces o tribunales se ha de ejercer del modo prescrito por el derecho, y no puede delegarse, si no es para realizar los actos preparatorios de un decreto o sentencia (Pablo II, 1989).

En lo atinente a esta última potestad García Martín (2010), precisa:

La potestad judicial es aquella función de la potestad de gobierno que resuelve los conflictos, las cuestiones controvertidas. Esta potestad, como se ha tenido ocasión de ver (can. 16 No. 3), aplica la ley, por lo cual tiene su propio fundamento en la ley y está subordinada a la potestad legislativa. Los legisladores personales, por tanto, son titulares de la potestad judicial, sin embargo, desempeñan su tarea por medio de los jueces y de los tribunales (García Martín, 2010, p.405).

Más adelante el Código de Derecho canónico establece:

\section{Canon 1401. La Iglesia juzga con derecho propio y exclusivo:}

1. las causas que se refieren a cosas espirituales o anejas a ellas ${ }^{14}$;

principalmente al Código de Occidente de 1983.

14. Queda claro que la jurisdicción y competencia de la Iglesia es respecto de sus propias leyes y súbditos, es así que el Estado puede juzgar a sus ciudadanos católicos si estos infringen sus leyes, por eso encontramos Sentencias de Tribunales que pertenecen a la Jurisdicción del Estado, en donde una de las partes es un miembro de la Iglesia; los casos más sonados se dan cuando una de las partes es un sacerdote o religioso que demanda un derecho o que es sancionado por un delito o por su responsabilidad civil. Ejemplo de ello son los siguientes fallos: SU540 de 2007. 
2. La violación de las leyes eclesiásticas y de todo aquello que contenga razón de pecado, por lo que se refiere a la determinación de la culpa y a la imposición de penas eclesiásticas.

Canon 1402. Todos los tribunales de la Iglesia se rigen por los cánones que siguen, quedando a salvo las normas de los tribunales de la Sede Apostólica.

De Paolis ( 2012), citando a Arroba Conde expresa:

(...) la potestad judicial es aquel sector de la potestas regiminis al que se confía la aplicación estricta de la ley en los casos de conflicto que tienen en su base, en forma directa o indirecta, un derecho subjetivo controvertido y que, a iniciativa legítima y exclusiva de los interesados, requiere una solución autoritativa. Las decisiones propias de la autoridad judicial son las sentencias y los decretos judiciales que tienen por objeto la interpretación y aplicación de la ley al caso concreto, si bien éstos serán válidos y eficaces solo si el poder judicial obró siguiendo las normas del proceso que, además de reconocer a los interesados la iniciativa de la prueba practicada, establecen su participación contradictoria modo iure praescripto (p. 166).

1.3.- Cabe resaltar que las modificaciones hechas por el Santo Padre en el Motu proprio, se limitan al procedimiento en las causas de nulidad del matrimonio, que son competencia exclusiva de los Tribunales Eclesiásticos, en contraposición a las jurisdicciones civiles.

Constantino ${ }^{15}$, emperador romano, expidió el Edicto de Milán (313 d.C.) "con el cual el Estado romano se comprometió a respetar la libertad de cultos permitiendo a los cristianos hacer pública su profesión de fe, en igualdad de condiciones

15. Constantino ya enfermo se hizo bautizar y es el primer emperador Cristiano de la historia. También dicen los historiadores que debido a que Roma continuaba con sus prácticas paganas traslado la capital del imperio a Bizancio, a la que recuperó y llamó Nueva Roma y a la q después en su honor llamarían Constantinopla.

16. Dice el autor "Los obispos entienden en estas materias como los jueces civiles y con su misma autoridad. Pero este privilegio fue efímero. Sin embargo, los obispos conservarán el derecho de juzgar en las causas matrimoniales que les sean sometidas por ambas partes de común acuerdo".

17. Cabe precisar que el imperio romano de occidente es el que cae con la entrada de los Barbaros en el siglo V, porque el Imperio romano de oriente solo caerá en el siglo XV cuando los Turcos se toman Constantinopla (hoy Estambul - Turquía) y una razón con otras religiones" (Novoa Parra, 2008, p. 121), también ${ }^{16}$ "en tiempo de Constantino se le concede a los obispos cierta jurisdicción sobre las causas matrimoniales" (Jaeger, 1960, p.216). En el siglo VI, dice Pierre Adnés (1969):

(...) cuando el imperio romano pasa a manos de los bárbaros ${ }^{17}$, la Iglesia pasa a tener sus propios tribunales que juzgarán en concurrencia con los tribunales civiles las causas matrimoniales.... El debilitamiento creciente del poder real en el curso del siglo X hará pasar definitivamente a manos de la Iglesia la jurisdicción entera y exclusiva del matrimonio. La conservará hasta el siglo XVI (p.223) ${ }^{18}$.

La jurisdicción y competencia de la Iglesia, en el tema matrimonial, en contraposición a las jurisdicciones civiles, fue definida en el Concilio de Trento (1545 - 1563). Javier Hervada (2000) al respecto precisa:

De modo explícito el Concilio definió: a) la potestad de la Iglesia para constituir impedimentos dirimentes y dispensar de ellos; b) la competencia para juzgar causas matrimoniales. De modo implícito quedó definido -entre otras cosas- que la Iglesia posee dicha jurisdicción por derecho propio, no por concesión de autoridades civiles (p. 213).

Esta potestad de régimen, referente al matrimonio católico, dado su carácter sacramental ${ }^{19}$, tiene un especial significado que se evidencia en dos propiedades esenciales: la indisolubilidad y la unidad ${ }^{20}$, por esto mismo Pérez Tortosa, F (2010) dirá:

La Iglesia católica siempre ha reclamado para sí la competencia sobre los matrimonios de los

más para que existan dos códigos de derecho canónico, el de oriente y el de occidente obedece también en parte a esa división territorial del Imperio Romano.

18. Con el protestantismo y las tesis del regalismo, por mucho tiempo, será desconocida esta jurisdicción, pero en ella se insistirá expresamente en el canon 12 del Concilio de Trento.

19. Canon 1055: \& 1. La alianza matrimonial, por la que el varón y la mujer constituyen entre sí un consorcio de toda la vida ordenado por su misma índole natural al bien de los cónyuges y a la generación y educación de la prole, fue elevada por Cristo Señor a la dignidad de sacramento entre bautizados. \& 2. Por tanto, entre bautizados, no puede haber contrato matrimonia válido que no sea por eso mismo sacramento."

20. Canon 1056: Las propiedades esenciales del matrimonio son la unidad y la indisolubilidad, que en el matrimonio cristiano alcanzan una particular firmeza por razón del sacramento. 
bautizados en atención, sobre todo, al principio de inseparabilidad entre el pacto matrimonial y el sacramento, entendido de forma tal -como se apuntó anteriormente- que donde hay un matrimonio válido entre bautizados necesariamente opera el sacramento. La Iglesia católica ha ejercido desde su fundación esta potestad legislativa, administrativa y judicial sobre el matrimonio de los bautizados, ya que lo considera un derecho propio.

Tres son las razones que se esgrimen para defender esta posición.

En primer lugar, que es un derecho concedido por Cristo a la Iglesia en su misma constitución, por lo que no deriva de ningún tipo de concesión por parte de la autoridad civil.

En segundo lugar, que es un derecho exclusivo en todo lo que se refiere a la constitución del vínculo matrimonial y a cuanto deriva del vínculo, por lo que la potestad civil queda limitada a los efectos meramente civiles del matrimonio.

La tercera y última causa se basa en que es un derecho independiente, entendido como que la Iglesia, en el ejercicio de este derecho, no depende de ninguna autoridad humana, si bien, como es obvio, tiene que tener presentes las circunstancias sociopolíticas en cada tiempo y lugar para poder ejercer con prudencia su propia autoridad (p. 153).

1.4. La potestad de la Iglesia sobre el Matrimonio en el Código de Derecho Canónico:

Canon 1059 El matrimonio de los católicos, aunque sea católico uno solo de los contrayentes, se rige no sólo por el derecho divino, sino también por el canónico, sin perjuicio de la competencia de la potestad civil sobre los efectos meramente civiles del mismo matrimonio ${ }^{21}$.

21. Lo relativo a la competencia sobre los efectos civiles también lo regula el canon 1672.

22. Canon 1673 Para las causas de nulidad de matrimonio no reservadas a la Sede Apostólica, son competentes: $1^{\circ}$ el tribunal del lugar en que se celebró el matrimonio... en que el demandado tiene su domicilio... la actora...

23. La disolución del vínculo matrimonial no se permite en la Iglesia, conforme a lo establecido en el canon 1141. Solo se podrán disolver de acuerdo al canon 1142 "El matrimonio no consumado..." y según el canon 1143 en virtud del privilegio paulino entre no bautizados. Por otra parte cabe aclarar que tratándose solo de separación de cuerpos, por vía de Concordatos celebrados con los diferentes Estados, la Iglesia reconoce la jurisdicción del Estado, tal como se consagró expresamente en el Artículo IX de la Ley 20 de
El mismo Código de Derecho Canónico dentro de los procesos especiales que rigen a la Iglesia regula el fuero competente para los procesos matrimoniales: "Canon 1671 Las causas matrimoniales de los bautizados corresponden al juez eclesiástico ${ }^{22}$ por derecho propio". Este canon debe entenderse ${ }^{23}$, en lo referente a las nulidades y disolución del vínculo matrimonial.

\section{El reconocimiento de la Potestad de Régimen en Colombia}

Desde que se promulgó la Constitución de 1886, en la que se reconocía el catolicismo como la religión de la Nación, se suscribieron dos Concordatos entre la Santa Sede y el Estado Colombiano en los que se reconocía expresamente dicha potestad, veamos:

2.1 Concordato del 31 de Diciembre de 1887, aprobado por la Ley 35 de 1888

Artículo 2.- La Iglesia Católica conservará su plena libertad e independencia de la potestad civil, y por consiguiente sin ninguna intervención de esta podrá ejercer libremente autoridad espiritual y su jurisdicción eclesiástica, conformándose en su gobierno y administración con sus propias leyes.

Este artículo concuerda con el artículo $53^{24}$ de la Constitución de 1886 que le reconocía capacidad jurídica y el derecho para ejercer actos de autoridad espiritual y administrativa. Dice Florez García (1975):

Y cuando el Concordato habla de libre ejercicio de la Iglesia según su propia naturaleza, ¿qué abarca? Ciertamente que se refiere: a los sacramentos y sacramentales..., que su vida sea santificada con el sacramento del matrimonio, cosas que a más de ser de orden interno lo son en el orden externo y social (p. 37).

2.1.1 En este punto cabe expresar también que el Concordato de 1887 en sus artículos 17 y 18 le reconoció efectos civiles a los matrimonios católicos y en su artículo 19, reza:

1974, aprobatoria del Concordato "Las Altas Partes Contratantes convienen en que las causas de separación de cuerpos de los matrimonios canónicos sean tramitadas por los jueces del Estado, en primera instancia ante..."

24. Art. 53 Constitución 1886.- "La Iglesia Católica podrá libremente en Colombia administrar sus asuntos interiores, $y$ ejercer actos de autoridad espiritual y de jurisdicción eclesiástica sin necesidad de autorización del Poder civil." 
Serán de la exclusiva competencia de la autoridad eclesiástica las causas matrimoniales que afecten el vínculo del matrimonio y la cohabitación de los cónyuges, así como las que se refieren a la validez de los esponsales. Los efectos civiles del matrimonio se regirán por el Poder civil.

2.2. Concordato del 13 de Junio de 1973, aprobado por la Ley 20 de 1974

Este Concordato en los artículos primero y segundo también reconoció la potestad y jurisdicción de la Iglesia. Respecto al matrimonio se consagra en los siguientes artículos:

ARTÍCULO VII: El Estado reconoce plenos efectos civiles al matrimonio celebra-do de conformidad con las normas del derecho canónico. Para la efectividad de es-te reconocimiento la competente autoridad eclesiástica transmitirá copia auténtica del Acta al correspondiente funcionario del Estado quien deberá inscribirla en el re-gistro civil.

ARTíCULO VIII: Las causas relativas a la nulidad o a la disolución del vínculo de los matrimonios ca-nónicos, incluidas las que se refieren a la dispensa del matrimonio rato y no consu-mado, son de competencia exclusiva de los Tribunales Eclesiásticos y Congrega-ciones de la Sede Apostólica. (Subrayado fuera del original) ${ }^{25}$.

Con la promulgación de la Constitución Política de 1991 y dado su carácter secular, algunos juristas demandaron la inexequibilidad del Concordato y de la Ley aprobatoria, por considerar que el pronunciamiento de la Corte Suprema como resultado del control de constitucionalidad de la ley en su momento, se hizo bajo los principios de la Carta del 86, razón por la cual se declaró inhibida para pronunciarse de fondo en cuanto al contenido del mismo, por tratarse de un Tratado Internacional.

25. Ley 25 de 1992.- ARTÍ́CULO 3o. El artículo 146 del Código Civil quedará así: El Estado reconoce la competencia propia de las autoridades religiosas para decidir mediante sentencia u otra providencia, de acuerdo con sus cánones y reglas, las controversias relativas a la nulidad de los matrimonios celebrados por la respectiva religión". ARTÍCULO 4o. El artículo 147 del Código Civil quedará así: Las providencias de nulidad matrimonial proferidas por las autoridades de la respectiva religión, una vez ejecutoriadas, deberán comunicarse al juez de familia o promiscuo de familia del domicilio de los cónyuges, quien decretará su ejecución en cuanto a los efectos civiles y ordenará la inscripción en el Registro Civil.
Consideran que corresponde de acuerdo con el nuevo ordenamiento asumir el control de constitucionalidad por la Corte Constitucional a la luz de la nueva Carta Política, porque a juicio de los accionantes tanto el Concordato como la ley que lo aprobó resultan violatorios de diferentes preceptos constitucionales de la carta del 91.

Al respecto se traen a colación las consideraciones de la Corte Constitucional, expresadas en la sentencia C-027 de 1993, M.P. Simón Rodríguez, respecto de los artículos II y III $^{26}$ del Concordato y de la ley aprobatoria, que se refieren al reconocimiento de la jurisdicción eclesiástica por parte del Estado y el VIII relacionado con la nulidad o disolución de los matrimonios católicos,

Se ha dicho que el concordato es un tratado internacional entre dos personas, es decir, entre el Estado Colombiano y la Santa Sede. Este tratado tiene sus particularidades especiales porque la gran mayoría de sus cláusulas van dirigidas para que se cumplan dentro del territorio colombiano, con unos sujetos específicos como son los habitantes en territorio colombiano que pertenecen a la Iglesia católica, apostólica y romana, a los sacerdotes y jerarcas de esta Iglesia por un lado y por el otro, a las autoridades de la República. Vale decir, que el tratado tiene plena operatividad y vigencia práctica dentro de Colombia.

(...) El pluralismo político y religioso instaurado en la Carta de 1991 permite la coexistencia de ordenamientos, entre ellos, unos religiosos, de las distintas confesiones, incluida la católica, y otros políticos (del Estado). Una manifestación entonces de la libertad religiosa (art. 19 C.N.) es la de aceptar la independencia y autonomía eclesiástica de la Iglesia Católica, como una realidad viviente y hecho sociológico e indiscutible del pueblo colombiano (...) (Subrayado fuera del original).

En cuanto al tema específico del matrimonio dice el Concordato:

26. 1.- Artículo II La Iglesia Católica conservará su plena libertad e independencia de la potestad civil y por consiguiente podrá ejercer libremente toda su autoridad espiritual y su jurisdicción eclesiástica, conformándose en su gobierno y administración con sus propias leyes.

2.- Artículo III La Legislación Canónica es independiente de la civil y no forma parte de ésta, pero será respetada por las autoridades de la República. 
3.- Artículo VIII Las causas relativas a la nulidad o a la disolución del vínculo de los matrimonios canónicos, incluidas las que se refieren a la dispensa del matrimonio rato y no consumado, son de competencia exclusiva de los tribunales eclesiásticos $^{27}$ y congregaciones de la Sede Apostólica.

La independencia entre la jurisdicción civil y eclesiástica, no excluye la colaboración armoniosa y respeto mutuo entre la Iglesia y el Estado, debiendo eso sí, precisarse que la colaboración pregonada en dicho artículo ha de referirse a la ejecución de los efectos civiles en los casos previstos en la Carta Política, esto es, los que tienen los matrimonios religiosos y las sentencias de nulidad de estos matrimonios.

Al respecto es necesario precisar aspectos de singular importancia como la independencia existente entre la jurisdicción civil y la jurisdicción eclesiástica, que con la Constitución Nacional del 91 se aclara de modo significativo.

Así las cosas, se tiene que respecto al matrimonio católico uno es el vínculo que surge del mismo y otro los efectos civiles que genera. Respecto al vínculo, precisamente por la independencia de las jurisdicciones, mas no de la plena autonomía de la eclesiástica, no le es dable al Estado entrar a regularlos cuando se trate de matrimonios religiosos, pero sí le es permitido en lo que hace a los efectos civiles del mismo (subrayado fuera del original).

Este artículo VIII del artículo 1ำ fue declarado exequible en la Sentencia C-027 del 5 de febrero de 1.993 de la Corte Constitucional, salvo en el aparte de su inciso $1^{\text {o }}$ que dice: "o la disolución del vínculo". Pues conforme al artículo 42 de la Constitución y a la ley 25 de 1992, el Estado Colombiano puede decretar la "cesación de los efectos civiles de los matrimonios religiosos", pero la misma Corte en su sentencia aclaró que dicha cesación no rompe el vínculo matrimonial eclesiástico, por cuanto es una jurisdicción

27. "La Conferencia episcopal de Colombia, reunida en 1970, solicitó a la Signatura Apostólica, encargada de los tribunales de la Iglesia en el mundo, la creación de cinco tribunales regionales de primera instancia en las siguientes sedes: Bogotá, Barranquilla, Cali, Medellín y Bucaramanga. El decreto de erección lo dictó la Conferencia episcopal el 3 de Marzo de 1972 y fue aprobado por la Signatura Apostólica el 19 del mismo mes y año. En fecha posterior y mediante el mismo trámite, fue creado el Tribunal regional de Manizales. El Tribunal único de apelación fue creado desde Agosto de 1967 en la ciudad de Bogotá". Tomado de http://tribunaleclesiasticomedellin.org.co/ tribunal-eclesiastico-regional-de-medellin/ eclesiástica en la cual el Estado no tiene injerencia. Al respecto Hervada (2000) precisa:

Si la competencia de la Iglesia es exclusiva, no cabe duda de que, en línea de principios, el Estado es incompetente sobre el matrimonio de los bautizados. Dentro de esta misma línea de principios habría que invocar ante el Estado el derecho de libertad religiosa, que lleva a que los cristianos se rijan por el Derecho canónico en lo que al matrimonio se refiere. En este sentido, el reconocimiento del matrimonio canónico por el Estado es también una consecuencia directa del derecho de libertad religiosa (p. 216).

Para concluir esta parte cabe decir que aún cuando la Constitución de 1991 declaró la libertad religiosa y en tal sentido dejó de lado la confesionalidad a la religión católica consagrada en la Constitución de 1886, es evidente que en Colombia la Iglesia Católica conserva el respeto que le da su potestad de régimen. En cuanto a la cesación de efectos civiles a los matrimonios religiosos por parte de la legislación civil ${ }^{28}$, esta se diferencia de la jurisdicción eclesiástica de los Tribunales Eclesiásticos regionales y el Tribunal Eclesiástico Único de Apelación, que siguen conociendo gran número de procesos de Nulidad de Matrimonios Católicos, razón por la cual la reforma hecha por el Papa Francisco se ha convertido en una esperanza para todos los que siendo católicos y se enfrentan al fracaso de su matrimonio religioso, no pierdan la oportunidad de mantenerse activos sacramentalmente en su vida religiosa.

2.2.1. Sentencias que ratifican lo expresado en el Concordato de 1973

(i) Sentencia de la Corte Suprema de Justicia, 30 de Abril de 1987, M.P. Eduardo García Sarmiento.

La actora presentó demanda de exequátur para que la Corte homologue en Colombia las sentencias que declararon la Nulidad de su matrimonio, proferidas por los Tribunales Eclesiásticos de

28. Ley 25 de 1992 en su artículo 5o, reza: "El artículo 152 de Código Civil quedará así: El matrimonio civil se disuelve por la muerte real o presunta de uno de los cónyuges o por divorcio judicialmente decretado. Los efectos civiles de todo matrimonio religioso cesarán por divorcio decretado por el juez de familia o promiscuo de familia. En materia del vínculo de los matrimonios religiosos regirán los cánones y normas del correspondiente ordenamiento religioso". 
Santiago de Chile y en consecuencia se ordene el registro de las mismas en el registro civil ${ }^{29}$. Al respecto el alto tribunal dijo:

La Corte, reiterando doctrina de vieja data, sentencias de 6 de Abril de 1956 ( T. LXXXII, Pág. 548) y de 18 de Octubre de 1961 ( T. XCVII, Pág. 127) recientemente expuso, luego del análisis de los artículos $3^{\circ}, 7^{\circ} \mathrm{Y} 8^{\circ}$ del concordato celebrado entre Colombia y la Santa Sede, aprobado por la Ley 20 de 1.974, así como del estudio de varios de los cánones contenidos en el Código de Derecho Canónico promulgado por el Papa Juan Pablo II el 25 de Enero de 1.983, que todo este sistema normativo demostraba que la legislación de la Iglesia Católica, incluido dentro de ella el matrimonio católico, no estaba, circunscrita en su imperio a los límites territoriales del respectivo Estado, sino que su ámbito de validez era de aplicación general; y que, por consiguiente, las causas atinentes a la anulación o a la disolución del vínculo conyugal no podían entenderse que eran de competencia exclusiva de los Tribunales Eclesiásticos existentes en Colombia, o de los establecidos en otro Estado, sino de todos los jueces de la Iglesia, fueran nacionales o extranjeros (Corte Suprema de Justicia, 1987). Díaz

(ii) Sentencia T-285 de 1994. M.P. Fabio Morón

La actora alega - entre otras cosas - que el Tribunal Eclesiástico no ha respetado las normas civiles y procesales del ordenamiento Colombiano que permiten controvertir el dictamen pericial practicado en el proceso de nulidad, expedir copias etc. La Corte consideró:

Luego, no cabe duda de la existencia y habilitación, por mandato de la Constitución, de jurisdicciones eclesiásticas, lo que hace que, mediante la acción de tutela no puedan suplantarse esas jurisdicciones, y menos aún, imponerse en ellas decisiones judiciales que puedan obstaculizar

29. El artículo 693 del C.P.C. reza: "Efectos de las sentencias extranjeras. Las sentencias y otras providencias que revistan tal carácter, pronunciadas en un país extranjero en procesos contenciosos o de jurisdicción voluntaria, tendrán en Colombia la fuerza que les concedan los tratados existentes con ese país, y en su defecto la que allí se reconozca a las proferidas en Colombia. ..." Queda claro que las Sentencias de Nulidad no necesitan exequatur para ser reconocidas, lo único que exige el Estado Colombiano es el trámite ante el Juez de Familia que ordena el efecto propio de la Nulidad, es decir su registro en las actas del estado civil. su autónomo funcionamiento. Autonomía que no puede entenderse, ni la larga tradición jurídica de la Iglesia Católica en el mundo de occidente permite suponerlo en el caso concreto, como una prerrogativa sin fronteras que pueda alterar el concepto integrador de la vida social, propio de las decisiones judiciales, menos aún cuando se ocupen de instituciones de tanto valor social como el vínculo matrimonial, su nulidad y sus efectos civiles, sociales y éticos (Corte Constitucional, 1994).

(iii) Sentencia T-200 de 1995. M.P. José Gregorio Hernández

Varias madres demandan a la Arquidiócesis de Manizales por no autorizar el bautizo a sus hijos en la Iglesia Católica y se desarrolla el concepto de libertad religiosa. La Corte consideró:

Según el Preámbulo de la Constitución, ésta fue decretada, sancionada y promulgada invocando la protección de Dios.

Si bien el Estado no asume posiciones a favor o en contra de confesiones determinadas, ni se afilia a ninguna de ellas, toda vez que no hay en Colombia una religión oficial, tampoco desdeña las creencias del pueblo, a las cuales respeta y hace respetar, disponiendo los elementos normativos indispensables para asegurar que sea efectiva la libertad de cultos y absteniéndose de interferir en las funciones espirituales que cumplen los prelados y apóstoles de los distintos movimientos religiosos.

El Estado -dice el artículo 2o de la Ley 133 de 1994- no es ateo, agnóstico o indiferente ante los sentimientos religiosos de los colombianos.

En cuanto a la Iglesia Católica, cuya fe es profesada por la mayoría de la población, el Estado no le brinda trato preferente en detrimento de los demás cultos, ya que la diversidad de creencias no puede constituir motivo de desigualdad o discriminación ante la ley y las autoridades, pero es claro que -como lo expresa el artículo 11 de la mencionada Ley Estatutaria- continúa reconociéndole personería jurídica de Derecho Público Eclesiástico, lo cual es extensivo a las entidades erigidas o que se erijan conforme a lo establecido en el inciso $1^{\circ}$ del artículo IV del Concordato celebrado en 1973 entre Colombia y la Santa Sede, aprobado por la Ley 20 de 1974 y en vigencia desde el 2 de julio de 1975. 
La Iglesia Católica no depende de las autoridades estatales para desarrollar su papel espiritual en el seno de la sociedad colombiana y que no puede ser limitada por aquéllas, corregida u obligada, en lo que concierne específicamente a asuntos de índole religiosa, librados de modo exclusivo a sus principios y normas, que no provienen de la potestad civil y que no se deben a ella. La Iglesia Católica -como todas las religiones que operan en Colombia- puede señalar, sin autorización del Estado, de acuerdo con los lineamientos fundamentales de la fe religiosa y de conformidad con las decisiones de sus propias autoridades, las condiciones y requisitos que deben cumplirse para acceder a los sacramentos, que son elementos típicamente religiosos en cuya administración no intervine la potestad civil, ni para impedirla ni para propiciarla. Uno de ellos es el Bautismo. Se trata de un asunto ajeno a la autoridad de la legislación positiva del Estado y sustraído, por tanto, a las decisiones de los jueces, los cuales nada pueden resolver acerca de si el aludido sacramento se imparte o no a determinadas personas, ya que las exigencias previas son también religiosas y están reservadas a la autoridad eclesiástica (Corte Constitucional, 1995).

(iv) Sentencia T-946 de 1999. M.P. Antonio Barrera Carbonell

Un recluso de la Cárcel de Bellavista, alega discriminación, violación al derecho a la igualdad y libertad religiosa, porque el Capellán no quiso oficiar el matrimonio con su compañera permanente dentro del mismo establecimiento carcelario. La Corte consideró:

Las decisiones de las autoridades o representantes de la Iglesia Católica, que se ciñen exclusivamente al ejercicio de su culto o se amparan esencialmente en sus fundamentos doctrinarios, se adoptan de manera independiente por ellas, sin ninguna injerencia de la autoridad civil, de la misma forma que el Estado adopta sus determinaciones sin consultar y menos requerir del visto bueno de las iglesia o sus jerarcas (Corte Constitucional, 1999).

(v) Sentencia T-998 de 2002. M.P. Jaime Córdoba Triviño

La abogada de los padres y ex compañera de un policía fallecido, interpuso acción de tutela porque el Tribunal Eclesiástico Regional de Cali se negó a recibirle la demanda de Nulidad del matrimonio contraído por el fallecido con una tercera persona. Alegó la vulneración al derecho a la administración de justicia y al debido proceso. La Corte consideró:

[...] lo primero que debe tenerse en cuenta es que en Colombia, la autoridad eclesiástica es independiente de la autoridad civil.

Tal independencia se remonta al artículo 16 de la Ley 153 de 1887, de acuerdo con el cual " $L a$ legislación canónica es independiente de la civil, y no forma parte de ésta; pero será solemnemente respetada por las autoridades de la República". Esa situación fue ratificada primero por el Concordato firmado en Roma el 31 de diciembre de 1887 y ratificado por la Ley 35 de 1888 y luego por el Concordato suscrito en Bogotá el 12 de julio de 1973 y aprobado mediante Ley 20 de 1974.

Ello es así al punto que el artículo II del Concordato vigente dispone que "La Iglesia Católica conservará su plena libertad e independencia de la potestad civil y por consiguiente podrá ejercer libremente toda su autoridad espiritual y su jurisdicción eclesiástica, conformándose en su gobierno y administración con sus propias leyes" (subrayas no originales). Por su parte, según el artículo III, "La legislación canónica es independiente de la civil y no forma parte de esta, pero será respetada por las autoridades de la República". Estas disposiciones fueron declaradas exequibles por esta Corporación al decidir varias demandas de inconstitucionalidad formuladas contra la Ley 20 de 1974, aprobatoria del Concordato $[\ldots]$

4. En las condiciones expuestas, cuando los Tribunales Eclesiásticos tramitan procesos de nulidad de matrimonio católico, lo hacen como autoridades eclesiásticas y en ejercicio del poder jurisdiccional que les otorga el Concordato de 1974, aprobado por la Ley 20 de 1974; autoridades adscritas a la Santa Sede como persona de derecho internacional público eclesiástico y con independencia del Estado colombiano. De allí que no puedan ser calificados como particulares que tienen a cargo la prestación del servicio público de justicia en casos determinados pues su naturaleza jurídica no sólo es diversa sino también independiente de la autoridad civil y política del Estado colombiano.

De acuerdo con el Concordato, como tratado de derecho internacional público vigente, el Estado se ha comprometido a reconocer la independencia 
y autonomía de las autoridades eclesiásticas y de allí que en materia de procesos de nulidad de matrimonio católico sólo le sea posible reconocer los efectos civiles generados por la sentencia definitiva que declare la nulidad. Por fuera de ese efecto, cualquier cuestionamiento del proceder de las autoridades eclesiásticas, y de los Tribunales Eclesiásticos, entre ellas, debe plantearse ante esa jurisdicción y no ante las autoridades civiles colombianas. De lo contrario, se estarían desconociendo compromisos de derecho internacional público vigentes y avalados por esta Corporación pues los principios pacta sunt servanda y de buena fe son reconocidos en los artículos 26 y 27 de la Convención de Viena sobre Derechos de los Tratados, de la cual Colombia es parte.

5. En las condiciones expuestas, al Tribunal Eclesiástico Regional de Cali no puede dársele el tratamiento de un particular en los términos del artículo 86 de la Constitución Política pues se trata de una autoridad eclesiástica sometida a las jerarquías de la Iglesia Católica como persona de derecho público eclesiástico y no a las autoridades colombianas (Corte Constitucional, 2002) ${ }^{30}$.

(vi) Sentencia C-074 de 2004. M.P. Clara Inés Vargas Hernández

El demandante manifiesta que el artículo 14 transitorio de la Ley 25 de 1992 es inconstitucional por vulnerar los artículos $4,9,29,42$ incisos $6,9,11,12$ y 224 de la Constitución, al convalidar sentencias civiles de divorcio del matrimonio canónico, que jamás debieron haberse producido, porque a los jueces civiles -tanto por norma concordataria como por disposiciones constitucionales- les estaba vedado el conocimiento y el trámite de los procesos de los divorcios vinculares de los matrimonios canónicos.

El conocimiento de las disputas sobre la disolución del vínculo canónico es de las autoridades eclesiásticas, en contraposición con lo que estatuye la Carta Política en el sentido de consagrar el

30. Ley 133 de 1994 "ARTÍCULO 13. Las Iglesias y confesiones religiosas tendrán, en sus asuntos religiosos, plena autonomía y libertad y podrán establecer sus propias normas de organización, régimen interno y disposiciones para sus miembros. ... PARÁGRAFO. El Estado reconoce la competencia exclusiva de los tribunales eclesiásticos para decidir, lo relativo a la validez de los actos o ceremonias religiosas que afecten o puedan afectar el estado civil de las personas". divorcio como institución que hace cesar los efectos civiles de todo matrimonio, que al no consagrar excepción incluye toda forma matrimonial: la civil y la de cualquier religión; lo que no significa que el divorcio que de decrete dentro de un matrimonio canónico rompa el vínculo matrimonial, pues ese divorcio no quebranta las observaciones de la ley canónica ni interrumpe el vínculo eclesiástico, sino que termina con los efectos civiles del matrimonio de acuerdo con el artículo 42 de la Constitución".

Cabe recordar, que la Corte Constitucional al efectuar el control respectivo a la ley aprobatoria del Concordato y en efecto al mismo tratado, consideró que el pluralismo político y religioso instaurado en la Carta de 1991 permite la coexistencia de ordenamientos, entre ellos, unos religiosos, de las distintas confesiones, incluida la Católica, y otros políticos (del Estado) (...)

Con la Constitución de 1991 quedó claro de modo significativo además, la independencia existente entre la jurisdicción civil y la jurisdicción eclesiástica. Es decir, que respecto del matrimonio Católico uno es el vínculo que surge del mismo y otro los efectos civiles que genera. Respecto del vínculo, precisamente por la independencia de las jurisdicciones, más no de la plena autonomía eclesiástica, no le es dable al Estado entrar a regularlos cuando se trate de matrimonios religiosos, pero sí le es permitido en lo que hace a los efectos civiles del mismo. Por lo tanto, los efectos civiles del matrimonio pueden cesar por el divorcio con arreglo a la ley civil, lo cual no desconoce la validez del matrimonio católico, ni le impide a los creyentes contraer nupcias siguiendo los lineamientos que para el caso prevean las normas que las regulan (Corte Constitucional, 2004).

En Salvamento de Voto de los Magistrados Marco Gerardo Monroy y Rodrigo Escobar a la sentencia referenciada se dijo:

Con fundamento en el artículo 3 del Concordato, la Corte [Suprema de Justicia] en sentencia de 15 de mayo de 1945 (G.J.t.LXXVII, núm.2141, p.580), reiterada en la del 30 de noviembre de 1961 (G.J.t. XCV, núms. 2235-2236), expresó que existe el respeto del derecho canónico por referencia formal, lo cual implica que las leyes eclesiásticas son admitidas por el derecho civil "con las características intrínsecas y la vigencia y validez que tienen en el ordenamiento de origen" como emanadas de una persona pública de derecho público eclesiástico como es la Iglesia. 
Por lo tanto, según lo anota la sentencia de 15 de mayo de 1954 existe "imposibilidad de considerar que pueda haber conflicto entre la norma civil y la eclesiástica, pues cuando el derecho del Estado defiere formalmente a una institución de derecho canónico, con deferencia implica que el derecho civil admite la reglamentación canónica relativa a esa institución" (Corte Constitucional, 2004).

\section{Reseña histórica del aspecto procesal de la consulta y su consagración en la legislación procesal en colombia}

3.1. Es pertinente precisar que en la historia de las fuentes del derecho civil - Ius civile - estudiado principalmente en el Derecho Romano ${ }^{31}$, en algunos períodos de su historia, el Derecho natural y el Derecho Canónico - Ius canonicum - co-existieron con el civil, y su contribución a la técnica jurídica fue enorme y en al-gunos temas el derecho civil la mantuvo, tal como lo expresan Maldonado y Del Toro (1975):

Por eso no resulta extraño que, una vez cristianizado el Imperio romano (Ley Cunctos populos del año 380 ), se produjesen en instituciones concretas del Derecho de éste mu-chas transformaciones, tan importantes que Biondo Biondo ha podido estudiar con de-tenimiento el sistema de un Derecho romano cristiano, el cual muestra la influencia de la patrística (San Ambrosio ... San Agustín) , con su empuje humanitario y espiritualista, en normas recogidas en los textos civiles (Codex y Novellae)... se organiza la administración de justicia por los obispos en materia civil (episcopalis audientia) ...

Como más importantes entre los principios que inspiraron la dicha acción del Derecho ca-nónico en el campo jurídico general y, por consiguiente, su aportación al Derecho civil pueden señalarse un principio de adecuación de las normas a las exigencias de la justi-cia... Principio de justicia, la equidad, la buena fe... (Subrayado fuera del original)

31. Dependiendo de las fuentes que inspiran un derecho determinado, en un comienzo y para facilitar su estudio, el mundo se dividió en familias o sistemas jurídicos: Sistema RomanoGermánico-Francés, al que pertenece Colombia y dentro del cual se desarrolló el Derecho Canónico; el Sistema del Common Law los Sistemas Teocráticos; Los Sistemas Socialistas y los Sistemas Orientales. Hoy día se dan otras clasificaciones, pero para efecto de nuestro estudio nos remitimos a la clasificación inicial.

32. "La Constitución Francesa de 1791 fue la que introdujo el principio de que no se consideraba al matrimonio más que como
Las zonas de influencia más relevantes. --- 1.- El derecho de familia ... toda la materia relativa al matrimonio se construyese por las normas, las decisiones y la doctrina de los orga-nismos canónicos, los cuales fueron elaborando una nutrida legislación, una abundante práctica procesal y una copiosa doctrina jurídica ${ }^{32} \ldots 2$. . El derecho procesal. En el ambien-te del Derecho común... se formó en Italia desde el siglo XII un modo de actuación judi-cial, al que se dio el nombre de processus (en vez del antiguo romano de iudicium), muy elaborado... fue construido por los canonistas y las decretales de los papas para los tribunales canónicos y se extendió también a los civiles (p. 147) ${ }^{33}$ (subrayado fuera del original).

La Consulta de Sentencias de primera instancia en el Derecho procesal en general, es de vieja data y por lo mismo cabe recordar lo expresado por Piero Calamandrei (1953), refiriéndose a Italia, en el sentido de que lo que él expresa se predica de la normatividad procesal civil. El autor señala como hechos críticos en el derecho procesal y en la justicia en general, la "cordial desconfianza"34 y la "crisis de la legalidad"35, todo lo cual justificó que el legislador creara mecanismos de control dentro del ordenamiento procesal.

Es del caso precisar y reiterar que la consulta no es un recurso, pues no depende de las partes interponerlo. La consulta "es un grado de jurisdicción que habilita al superior jerárquico para revisar la legalidad de algunas providencias, por

un contrato civil: principio que a partir de allí, fue extendiéndose por las leyes civiles de diferentes países." Pág. 155

33. "Las compilaciones justinianas, redescubiertas en la segunda parte del siglo XI, y el Decretum de Graciano, formado en la primera mitad del XII, fueron la base sobre la que comenzó a alzarse, en el ámbito de la Universidad de Bolonia, una ciencia del Derecho, referido por una parte a las leges romanas y por la otra a los canones eclesiásticos ... Surgió así, del binomio - Ius vetus romanus, Ius novum canónico - formado por estos dos términos del utrumque Ius, un Ius Commune..."

34. "todo el ordenamiento burocrático recargado por cien controles se halla basado sobre la desconfianza del superior respecto del inferior... También el proceso civil se halla basado entre nosotros sobre esta desconfianza" páginas 305 y 306.

35. "El juez, al elegir entre dos soluciones, cree elegir la dictada por la férrea lógica del razonamiento: y, en cambio, elige sin darse cuenta aquella que más satisface su sentimiento.... El juez no solo es juez; es un ciudadano, es decir un hombre asociado, que posee determinadas opiniones o intereses comunes con otros hombres. No se halla solo, sino ligado por inconscientes solidaridades $y$ convivencias: es inquilino o dueño de casa; casado o célibe; hijo de comerciante o agricultores; pertenece a una iglesia y quizá, aunque no lo diga, a un partido..." página 313. 
mandato de la ley" (Corte Constitucional, 2003) ope legis - es decir por ministerio de la ley, pues protege un interés que considera público ${ }^{36}$, por lo mismo si opera la - reformatio in pejus ${ }^{37}$ (Corte Constitucional, 1997).

3.2. Refiriéndonos al caso Colombiano, cabe decir que el Grito de Independencia de España, no pudo darse plenamente, en lo que aquí nos ocupa - la ley procesal -, pues el Primer Código expedido por el Congreso en $1872^{38}$, se basó en el Código de Cundinamarca y éste a su vez había retomado la Ley de Enjuiciamiento Civil Española de 1855, ley que "se atuvo al derecho histórico nacional, que no era otro que el del proceso romano canónico o común recibido principalmente en las Partidas".

La Consulta la consagra la Constitución Política de Colombia en el artículo $31^{39}$.

3.3. La consulta en materia civil ya se encontraba consagrada en los artículos $508^{40}$ a $510^{41}$ de la Ley 105 de 1931; así como en el artículo 386 del CPC (Decretos1400 y 2019 de 1970), pero este artículo fue derogado expresamente por la Ley 1564 de 2012.

Los doctrinantes coinciden en que la derogatoria de "la Consulta obligatoria" para los casos señalados en la Ley civil ${ }^{42}$, obedece a la aplicación del principio de economía procesal, a la búsqueda de la descongestión procesal, al

36. En materia de Derecho Administrativo en la Sentencia T-246 de 2015 se expresó: el grado jurisprudencial de consulta procede en todos los casos en donde haya una condena en contra de una entidad pública, ... Sostuvo que lo anterior obedece a que la finalidad de la consulta es salvaguardar el patrimonio público;

37. "Cuando el superior conoce en grado de consulta de una decisión determinada, está facultado para examinar en forma íntegra el fallo del inferior, tanto por aspectos de hecho como de derecho y, al no estar sujeto a observar la prohibición contenida en el artículo 31 de la Carta, bien puede el juez de segunda instancia modificar la decisión consultada a favor o en contra del procesado, sin violar por ello norma constitucional alguna. La autorización que se otorga en el precepto demandado al superior para que al decidir la consulta se pronuncie "sin limitación" alguna sobre la providencia dictada por el inferior, no lesiona la Ley Suprema, pues de su propia esencia se deriva la capacidad del funcionario de segunda instancia para revisar íntegramente la providencia consultada con el único objetivo de corregir los errores en que haya podido incurrir el fallador de primera instancia. De esta manera se busca evitar que se profieran decisiones violatorias no sólo de derechos fundamentales sino de cualquier otro precepto constitucional o legal, en detrimento del procesado o de la sociedad misma como sujeto perjudicado con el delito. El propósito de la consulta es lograr que se dicten decisiones justas. Y la justicia es fin esencial del Estado". Ver también Sentencia T- 533 de 2001. hecho de que los curadores ad litem tienen unas responsabilidades procesales que deben cumplir y a que el juez hoy día tiene facultades de oficio para decretar pruebas que garanticen el debido proceso y la verdad material y procesal, por lo que se hace innecesaria la ratificación de la sentencia de primera instancia. En tal sentido la Sentencia C-874 de 2003 (M.P. Marco Gerardo Monroy Cabra), expresa:

(...) no rige más entre nosotros el esquema dispositivo, en donde la responsabilidad por el adelantamiento del trámite competía a las partes, pues ahora es el juez el verdadero impulsor del proceso, para lo cual la ley le atribuye poderes suficientes y le señala deberes y responsabilidades ineludibles. A la raíz de esta renovada visión legal del procedimiento subyace sin duda una nueva concepción que estima que el proceso civil involucra siempre un interés público. Este interés consiste en dar real aplicación al derecho de acceso a la Administración de Justicia mediante la obtención de un fallo proferido opor $\neg$ tunamente y que resuelva en el fondo el asunto sometido a la Jurisdicción, como garantía de la convivencia pacífica entre los asociados. Responde esta nueva concepción a la necesidad sentida de lograr la eficacia del sistema judicial, evitando la proliferación los métodos de justicia privada; es una respuesta política del legislador, determinada

38. Rodríguez Piñeres, E. (1908) Código Judicial adoptado por los Estados Unidos de Colombia por la Ley 57 de 7 de junio de 1872 y aplicado para la República de Colombia por mandato de la Ley 57 de 1887 art. 1, vigente hasta 1931. “...Art. 829. La sentencia que deba ser, consultada no se ejecutoría jamás mientras no se consulte. En consecuencia, es la sentencia sobre la consultada, la que tiene fuerza definitiva".

39. Art. 31. C.N.- "Toda sentencia judicial podrá ser apelada o consultada, salvo las excepciones que consagra la ley".

40. Art. 508 C.J. "Las sentencias que declaren alguna obligación a cargo del Estado, los Departamentos o los Municipios en primera instancia, deben ser consultadas con el Superior". Dice José A. Archila "que se conserva la disposición protectora de los intereses de la Nación..."

41. "ARTÍCULO 509.- Las consultas de autos o sentencias que este Código dispone se hagan por el Juez, en ciertos casos, se sustancian y deciden por el superior como las apelaciones, ARTÍCULO 510.- La sentencia que debe ser consultada, no se ejecutoria mientras no se surta la consulta."

42. La consulta obligatoria en materia civil también se daba para las Sentencias que decretaban la interdicción de una persona y en los que actuaba el curador ad litem en representación del demandado ausente. Esta consulta fue Derogada por la Ley 1395 de 2010. La consulta que se exigía en Sentencia contra de la Nación, los Departamentos, municipios... También fue Derogada por la Ley 1564 de 2012, actual Código General del Proceso. 
por los signos de los tiempos, que persigue que el Estado asuma con mayor desempeño la función pública de administrar justicia, por lo cual renueva la imagen del juez como director del trámite procesal, sustrayendo de las manos de las partes la impulsión del juicio (Corte Constitucional, 2003).

3.4. La Consulta en el Código de Procedimiento Laboral: El artículo 69, modificado por el art. 14 de la Ley 1149 de 2007, establece un grado de jurisdicción denominado "consulta", así: "las sentencias de primera instancia, cuando fueren totalmente adversas a las pretensiones del trabajador, serán necesariamente consultadas con el respectivo tribunal de trabajo si no fueren apeladas. También serán consultadas las sentencias de primera instancia”, esto cuando fueren adversas a la Nación, al Departamento o al municipio. La Sentencia C-424 de 2015 hizo extensible la consulta a las sentencias de única instancia, dado que en materia laboral dependiendo de la cuantía, hay procesos de única instancia donde también se justifica la protección que se busca con la consulta.

3.5. La Consulta en lo Contencioso Administrativo: El artículo 184. Del C.C.A.Modificado por el art. 57 de la Ley 446 de 1998. (actualmente derogado por el artículo 309 de la Ley 1437 de 2011), establecía:

Consulta. Las sentencias que impongan condena en concreto, dictadas en primera instancia a cargo de cualquier entidad pública que exceda de trescientos (300) salarios mínimos mensuales legales o que hayan sido proferidas en contra de quienes hubieren estado representados por curador ad

43. Rodríguez Piñeres, E. (1908). Código judicial colombiano y leyes vigentes que lo adicionan y reforman. Bogotá: librería americana. Código Judicial adoptado por los Estados Unidos de Colombia por la Ley 57 de 7 de junio de 1872 y aplicado para la República de Colombia por mandato de la Ley 57 de 1887 art. 1, vigente hasta 1931... Art. 1632. Cuando en los negocios en que haya lugar a seguimiento de causa se declare no haberlo respecto de alguno ó algunos de los sindicados, se les mandará poner en libertad si estuvieren privados de ella; y si el sobreseimiento fuera consultable, la consulta se surtirá inmediatamente, remitiendo al superior copia de lo conducente, sin suspender el juicio mientras se resuelve la consulta" (fue derogado por la Ley 105 de 1890 art 365).... Art. 1724. Si pasare el tiempo señalado en el artículo 1723 del Código Judicial sin que se apele de la sentencia definitiva, el Juez mandará que se consulte con el superior respectivo si el delito por que se procede tuviere señalada otra pena, el Juez en el caso expresado de no apelación contra la sentencia definitiva la declarará ejecutoriada y la mandará ejecutar. (Reformado por el art. 354 y derogado por el art. 365 de la Ley 105 de 1890)". Ver también Ley 906 de 2004. C.P.P.

Ley 40 de 1907 : “Art. 163. Las sentencias definitivas de los Jueces Superiores del Distrito Judicial se consultarán con el Tribunal litem, deberán consultarse con el superior cuando no fueren apeladas.

En los asuntos contenciosos de carácter laboral, solamente se consultarán las sentencias dictadas en primera instancia que impongan condena a cargo de la entidad pública, cuando de la respectiva actuación se deduzca que la demandada no ejerció defensa alguna de sus intereses (...).

La providencia sujeta a consulta no quedará ejecutoriada mientras no se surta el mencionado grado.

3.6. La Consulta en materia penal ${ }^{43}$ : El grado jurisdiccional de consulta existía para los procesos por delitos contra la administración pública cuya pena mínima no fuera inferior a cuatro años, o de las siguientes conductas punibles: narcotráfico, testaferrato, lavado de activos y enriquecimiento ilícito de particulares, así como para sentencias absolutorias, decisiones de preclusión de la investigación, cesación de procedimiento y devolución de bienes, objeto material a terceros o al sindicado. Dicha posibilidad de consultar al superior funcional tuvo vigencia hasta la declaración de inconstitucionalidad del art 203 del Código de Procedimiento Penal de 2000, ley 600 de ese año-, por la Corte en sentencia C-760 de $2001^{44}$.

Del mismo modo estuvo reconocida en la Ley 190 de 1995, art. 35 inciso 2 para la entrega definitiva de bienes a particulares en los delitos

Superior respectivo para que éste declare si el juicio adolece de nulidad, si el veredicto del Jurado es notoriamente injusto y si la ley penal ha sido rectamente aplicada."

Ley 105 de 1890 : "Art. 346. El auto de sobreseimiento se consultará, sino fuere apelado, en los negocios en que se pueda y deba procederse de oficio, siempre que el delito investigado sean de los que merecen penas corporales de muerte, presidio reclusión. En todo caso dicho auto es apelable por el respectivo Agente del Ministerio Público y por el acusador particular, si lo hubiere, y la apelación se concederá en efecto suspensivo".

Ley 100 de 1892 : "Art. 68. Cuando en los negocios en que haya lugar a seguimiento de causa se declare no haberlo respecto de alguno ó algunos de los sindicados, se les mandará poner en libertad si estuvieren privados de ella; y si el sobreseimiento fuera consultable, la consulta se surtirá inmediatamente, remitiendo al superior copia de lo conducente, sin suspender el juicio mientras se resuelve la consulta".

44. Ley 600 del 2000, Artículo 203. Consulta. INEXEQUIBLE. Cuando se trate de procesos por delitos contra la Administración Pública en los que la pena mínima no sea inferior a cuatro (4) años y en los delitos de narcotráfico, de testaferrato, de lavado de activos y de enriquecimiento ilícito de particulares, la preclusión de la instrucción, la cesación de procedimiento y la sentencia absolutoria se someterán a consulta con el superior, siempre que no hayan sido objeto de apelación. Esta Sentencia también declaró inexequible la expresión "consulta" de los artículos:5, 18, 19 y 20 de la misma Ley. 
contra la administración pública, así como para la sentencia que se abstuviese de declarar la extinción del derecho dominio (Ley 333 de 1996, art. 15 , literal g) ${ }^{45}$.

\section{Reseña Histórica de la Consulta en el Derecho Canónico.}

4.1. La doble instancia ${ }^{46}$ - duplex conformis obligatoria fue instituida en la Iglesia por Benedicto XIV en 1741, con la Constitución apostólica "Dei Miseratione" (GASPARRI-SERÉDI, 1939, p. 695701), ante los hechos que se venían presentando en su época de falta de rigor en los procesos de nulidad matrimonial. En tal sentido la Constitución apostólica "Dei Miseratione" manifiesta en la parte referida a la Indisolubilidad del Matrimonio:

1.- Que el vínculo del matrimonio, instituido por Dios, ha de ser perpetuo e indisoluble, en cuanto deber natural, en interés de la educación de los hijos y para salvaguarda del matrimonio; y que, por otra parte, en cuanto sacramento de la Iglesia, el vínculo matrimonial no puede ser disuelto por la audacia de los hombres, es algo que el Salvador mismo declaró con sus propios labios cuando dijo: "No separe el hombre lo que Dios ha unido" (Mt 19,6). Ahora bien, ha llegado a nuestros oídos el hecho de que, en ciertas cunas eclesiásticas, el vínculo matrimonial está siendo debilitado por la facilidad sumamente inconsiderada de los

45. En sentencia C 449 de 1996, sobre la finalidad de la Consulta en materia penal se dijo: "La razón de ser de esta figura procesal estriba en el interés especial que en ciertos casos asiste al legislador de evitar errores judiciales. En materia procedimental penal dicho interés es aún más trascendente, toda vez que los errores judiciales pueden llevar a causar gravísimos perjuicios a personas inocentes. La consulta, al permitir que el superior jerárquico revise la decisión del juez de primera instancia para confirmarla o modificarla, en todo o en parte, se erige como una garantía jurídica tanto para el sindicado como para el Estado, asi como para todas las demás personas que intervienen en el proceso. Por garantizar los derechos de todos los anteriores, y no solo del sindicado, su trámite es obligatorio y no es potestativo del juez si le da curso o no. En los casos en que resulta procedente, tanto el la-quo como el ad-quem deben tramitarla. Lo anterior, por supuesto, debe entenderse dentro del contexto del carácter subsidiario de este grado de jurisdicción; es decir, la consulta debe surtirse cuando los titulares del recurso de apelación no han hecho uso de él. En el caso contrario, esto es, cuando han interpuesto tal recurso, se cumple por esta vía con la misma finalidad de la consulta. Por lo cual su trámite pierde su razón de ser.

46. Dentro de los principios que inspiran el procedimiento civil, encontramos el de la doble instancia que comprende la organización jerárquica en la administración de justicia que garantiza el conocimiento en caso de impugnación por parte de un juez superior, en el caso de la apelación o en el de la consulta forzosa. jueces; y de que se dictan sentencias de nulidad de matrimonio con ligereza y sin reflexión, y se concede a los esposos la facultad de contraer nuevos vínculos. Por eso, sería oportuno que esos jueces -enteramente faltos de previsión-se dieran cuenta, por la condición de la naturaleza humana y en cierto modo también por su voz misma, de que no hay que quebrantar con tan peligrosa audacia el vínculo sagrado del matrimonio, que el primer padre del género humano anunciaba que tenía que ser perpetuo e indisoluble, cuando decía: "Esto sí que es ya hueso de mis huesos y carne de mi carne" (Gen 2, 23). Y el texto añade: "Por eso dejará el hombre a su padre y a su madre; y se adherirá a su mujer; y vendrán a ser los dos una sola carne" (Mt 19, 5; Gen 2, 24) (BENEDICTO, XIV (1741). (Subrayado fuera del original)

4.2.- El Papa Benedicto XIV, paralelamente y por la razón expuesta, crea la figura del Defensor del vínculo y a este le impone la obligación de velar por el sacramento del matrimonio y en su cabeza recae en un comienzo la consulta obligatoria del fallo de primera instancia que declare la nulidad del matrimonio, tal como lo expresa López (2010):

La cuestión de la confirmación de sentencias en las causas matrimoniales hay que ligarla al papel que tradicionalmente ha venido desarrollando en los procesos de nulidad el defensor del vínculo y resulta significativo que ambas instituciones tengan el mismo origen: la Constitución apostólica Dei Miseratione, promulgada por Benedicto XIV en el año 1741.

Benedicto XIV explica, a modo de cómo le llegan noticias de personas que preámbulo, contraen sucesivamente varios matrimonios debido a jueces que se precipitan en declarar la nulidad. El Pontífice se ve obligado a actuar ante esta situación. Establece la figura del defensor del vínculo que tiene un papel determinante puesto que está obligado a adherirse a la apelación de la parte que está en contra de la nulidad o, en cualquier caso, a apelar de oficio Hasta que no se resuelva esta apelación, las partes no pueden pasar a contraer nuevo matrimonio y sólo podrán hacerlo "sí secunda Sententia alter conformis fuerit, hoc est, si in secunda, aeque ac in prima, nullum ac irritum matrímonium iudicatum fueríf"(p. 2) (Subrayado fuera del original).

4.3. Esta apelación obligatoria por parte del Defensor del vínculo, como fue llamada por Benedicto XIV, se consagró expresamente en el canon 1986 del Código de Derecho Canónico de 1917. 
4.4. La Carta Apostólica Causas Matrimoniales del Papa Pablo VI de 1971 realizó algunas modificaciones al proceso, en relación al procedimiento en el tribunal de apelación, según lo expresa Marcelino Cabreros (1972), pues cuando va en segunda instancia para ratificar la Sentencia de Nulidad del Matrimonio, se dará un trámite abreviado de ratificación, diferente al trámite ordinario si se apela la Sentencia que negó la Nulidad, veamos:

a) Obligación de apelar contra la primera sentencia declaratoria de nulidad (norma VIII, § 1). La validez del vínculo matrimonial goza del favor del derecho por motivos de orden religioso y de orden social; y por esta causa no basta una sola sentencia declaratoria de nulidad sino que son necesarias, a lo menos, dos sentencias conformes. Contra la primera sentencia que declara la nulidad del matrimonio puede apelar la parte que se crea perjudicada o disienta del fallo dentro del plazo legal; y en todo caso puede pedir la revisión de la causa aunque, si han recaído dos sentencias, es preciso alegar nuevas pruebas (ce. 1903, 1989; Provida, n. 217). Pero el defensor del vínculo debe siempre apelar contra la primera sentencia declaratoria de nulidad, aun cuando crea que no hay objeción alguna que oponer a la sentencia dada. Ni siquiera la apelación interpuesta por la parte que se sienta perjudicada releva al defensor del vínculo de la obligación de apelar (Provida, arto 212, § 3).

Las normas VIII y IX van determinando cómo se ha de proceder cuando la sentencia, en ' primera instancia, resultó favorable a la nulidad del matrimonio. En cambio no se cuidan para nada del caso en que la sentencia sea favorable a la validez. Para el primer caso se 246 concede en el Motu proprio de Pablo VI un proceso judicial abreviado, en grado de apelación. Del segundo caso no se habla; lo cual quiere decir que no se concede el proceso abreviado y por lo tanto hay que seguir el proceso ordinario del Código (p. 225). (Subrayas fuera del original).

4.5. El Código de Derecho Canónico de 1983, cambió la apelación obligatoria del Defensor del vínculo, por la automática, en caso de que en la primera instancia se conceda la Nulidad del Matrimonio, veamos:

Canon 1682 \& 1 . La sentencia que declara por vez primera la nulidad de un matrimonio, junto con las apelaciones, si las hay, y demás actas del proceso debe transmitirse de oficio al tribunal de apelación dentro del plazo de veinte días a partir de la publicación de la sentencia (subrayado fuera del original).

Muchos doctrinantes consideraban necesaria la segunda instancia obligatoria, es el caso de De Paolis (2012), quien dice:

La necesidad de una doble sentencia conforme no es constitutiva de un proceso, ni siquiera de uno matrimonial. Pero forma parte de la experiencia humana cuan trabajoso es constatar la verdad y también prescindir de la malicia de los hombres. Por este motivo, en la práctica, los ordenamientos jurídicos prevén que una sentencia pueda siempre ser apelada, al menos en un segundo grado de juicio. En ocasiones, la verdad aparece luminosa y evidente desde un comienzo. En este último supuesto, el ordenamiento puede prever una vía más rápida, también desde el inicio. Hoy día la iglesia prevé siempre una segunda instancia, que debería ser tanto más necesaria cuando la sentencia de primer grado haya sido dictada por un juez único. También en este caso la iglesia prevé un doble camino: la ratificación por decreto y la admisión a examen ordinario. Pero permanece y debe permanecer firme el principio de la doble decisión conforme. La iglesia exige en modo particular la doble conforme para evitar errores contra la indisolubilidad del matrimonio, también con el recurso al processus brevior mencionado en el can. $1682 \S 2$ (p. 187).

Por su lado Pérez Tortosa, F (2010) plantea:

Como característica fundamental de los procesos matrimoniales, e independientemente de los recursos que las partes puedan ejercitar, la sentencia que declara la nulidad del matrimonio canónico en primera instancia debe enviarse "de oficio" al tribunal de apelación dentro de los veinte días desde su publicación junto con las apelaciones, si las hubiere, y las actas del proceso (1682 §1). La consecuencia más importante que tiene este canon es que la primera sentencia declarativa de la nulidad del matrimonio resulta insuficiente aunque la misma hubiese sido aceptada por todas las partes, tanto públicas como privadas. Al dejar de ser la posibilidad de la apelación un derecho de la parte que se considera lesionada por la sentencia, y producirse, por el contrario, el mecanismo de interposición del recurso de apelación de modo automático, el principio dispositivo decae a 
favor del principio de oficialidad, por lo que la apelación pasa de ser de una garantía de justicia para las partes a una garantía del resultado justo de la sentencia para la propia Iglesia católica. En este sentido, la apelación automática hace primar la verdad material sobre la verdad formal resultante de la sentencia. Ahora bien, podría pensarse que esta búsqueda de la verdad material sólo opera cuando se ha declarado la nulidad del matrimonio y no cuando la primera sentencia falla en contra de la nulidad. Si la necesidad de la apelación automática responde al favor del derecho del que goza el matrimonio, éste se materializaría mediante un recurso de apelación del defensor del vínculo, que sería de obligada interposición, y que garantizaría el principio dispositivo. Del mismo modo, si la búsqueda de la verdad material es la motivación principal de la existencia de la apelación de oficio, ésta debería operar independientemente del sentido del fallo de la primera instancia (p. 182-183) (subrayado fuera del original).

4.6. Cabe señalar que cuando la ley exigía dos sentencias que declararán la Nu-lidad del Matrimonio, ambas lo debían hacer por la misma razón o causal alegada, tal como lo exponen Cenalmor y Miras (2004).

Para que los cónyuges queden libres de contraer nuevo matrimonio, se requieren dos pronunciamientos conformes, es decir que dos tribunales de distinto grado declaren la nulidad de su matrimonio por la misma razón (cf. c. 1684). Por eso, la formulación del dubium en estos procesos debe plantear, no solo si consta la nulidad del matrimonio en el caso, sino también el capítulo o capítulos por los que se impugna su validez (cf. 1677\&3) (p. 541).

4.7. También es oportuno precisar que, a diferencia de lo que ocurre en el proce-so civil respecto a la cosa juzgada que se predica de las sentencias en firme, en materia de Derecho Canónico no sucede así, pues la nulidad se puede demandar nuevamente si se quiere, tal como lo aclaran Cenalmor y Miras,

(...) el canón 1643 establece que nunca pasan a cosa juzgada las sentencias sobre el esta-do de las personas (como son las que se dictan en procesos declarativos de nulidad ma-trimonial), de manera que, si surgen nuevas y graves pruebas o razones no consideradas en un proceso anterior sobre estas materias puede pedirse una nueva proposición de la causa (cf. C. 1644). La razón es la peculiaridad de esos procesos, en los que se dilucida la verdad del estado personal (2004, p. 538).
En igual sentido Martínez señalaba:

Se pueden apuntar las siguientes características del proceso matrimonial canónico:

1. Necesidad de doble instancia afirmativa o decreto confirmatorio de la primera sen-tencia que declare la nulidad para contraer nuevas nupcias (cc. 1.682-4).

2. Las causas matrimoniales nunca pasan de ser cosa juzgada, de modo que siempre ca-be una ulterior revisión (c. 1.643-4).

3. En las causas matrimoniales se prohíben los medios convencionales de terminación del proceso, como la transacción (1714), el compromiso arbitral (c. 1715) o el allana-miento (c. 1.446).

4. En las causas de nulidad y disolución debe intervenir el defensor del vínculo (c. 1432) o los actos serán nulos (c. 1433).

5. Los parientes son testigos hábiles en las causas matrimoniales.

6. Las causas de nulidad deben sustanciarse ante un tribunal colegial de tres jueces o cinco (c. 1425), salvo en el proceso documental (c. 1680) (Tirapu \& López-Sidro, 2004).

4.8. El Sínodo de Obispos congregado en 2014 para tratar los asuntos de la familia, dejó clara la problemática procesal que tenían que asumir muchas parejas para la nulidad de sus matrimonios y en tal sentido el Motu Proprio del Papa Francisco ${ }^{47}$, busca a través de una ley especial y breve solucionar dicha problemática, dejando así de lado, para el caso que nos ocupa, las consideraciones en favor de la segunda instancia obligatoria y busca sobre todo la celeridad en el proceso.

\section{La Reforma procesal en el Motu Proprio “Mitis Iudex Dominus Iesus" del Papa Francisco \\ Art. 4 - De la sentencia, sus impugnaciones y su ejecución}

47. El Cardenal Bergoglio venía de tiempo atrás (1999) estudiando y escribiendo sobre la familia y el matrimonio, fruto de lo cual en el 2013 se publicaron en la revista Familia y Vidacon, 35 textos sobre el tema. 
Can. 1679. La sentencia que por primera vez ha declarado la nulidad del matrimonio, cumplidos los términos establecidos en los cánones 1630-1633, se hace ejecutiva.

Sobre esto diferentes autores se han pronunciado:

5.1 Comunicado de prensa de Monseñor Pío Vito Pinto (precisiones acordes al artículo).

Objetivo de la Comisión especial instituida por el Papa Francisco el 27 de agosto de 2014 era la revisión solamente del orden procesal.

La reforma del Papa Francisco, movida por el mismo espíritu que sostuvo Benedicto $\mathrm{XI}>\mathrm{V}$ y Pío $\mathrm{X}$, se distingue sin embargo no solamente por una verdadera y propia refundación del proceso matrimonial canónico, sino sobre todo por los principios teológicos y eclesiológicos que la sostienen.

(...) No es ya solamente la hora del análisis, es la hora de actuar, de iniciar aquella obra de justicia y de misericordia esperada desde mucho tiempo...

Para comprender la tensión teológico jurídica que anima el motu proprio sobre el nuevo proceso de nulidad matrimonial es indispensable recibir la novedad del pontificado de Francisco, que resulta de una doble centralidad. Por una parte, el Evangelio de Cristo pone al centro a los pobres ${ }^{48}$. Por otra, resulta claro de la promulgación de esta nueva ley de justicia y misericordia, está la comprensión del ejercicio del ministerio como diakonía ("servicio"), en comunión indispensable los obispos a la cabeza de las iglesias en el mundo. (Pinto, 2014).

$5.2 \mathrm{El}$ auditor de la Rota Romana, monseñor Bunge relató:

Los puntos claves de la reforma los explicó:

4) Proceso ordinario:

- Rápido (un año como máximo).

- Abolición de la sentencia de doble conformidad (Es decir a la exigencia del derecho canónico, en

48. Respecto al tema de fe, el Papa pide una acogida a los divorciados, respecto de los cuales se debe hacer un esfuerzo pastoral en busca de su conversión y para el estudio de sus causas para ver si cabe la nulidad de sus matrimonios. Este tema merecerá un estudio posterior. el proceso declarativo de nulidad del matrimonio, de que haya dos sentencias conformes para que los cónyuges queden libres de contraer nuevo matrimonio. Esto implica que dos tribunales de distinto grado declaren la nulidad de un matrimonio por el mismo capítulo de nulidad y por las mismas razones de hecho y de derecho. n.d.r) (Subrayado fuera del original)

- La sentencia afirmativa no recurrida ipso facto es ejecutiva

- Si se propone el recurso después de una sentencia afirmativa este puede ser rechazado in limine, por la evidente falta de argumentos. Esto puede suceder en caso de apelación instrumental, para perjudicar a la otra parte; a menudo la parte recurrente no católica ya ha vuelto a casarse civilmente.

- De la reforma emerge la realidad, el principal motivo ahora de la masa de los católicos: consulere conscientiae; es decir, excluidos los aspectos de derecho civil, la nulidad se solicita por razones de conciencia (por ejemplo: vivir los sacramentos de la Iglesia, perfeccionar un nuevo vínculo, a diferencia del primero, estable y feliz!).

5) La rapidez del proceso va en la dirección de una limitación mayor de los recursos ante la Santa Sede, es decir a la Rota Romana, o del recurso a la Signatura Apostólica para la nueva presentación del caso, negado por la Rota (Bunge, 2015) (subrayado fuera del original).

5..expresa sobre el tema:

Queda abolida la sentencia de doble conformidad de manera que la sentencia afirmativa no recurrida será ejecutiva ipso facto (hasta ahora era necesaria en cualquier caso una segunda sentencia).

La sentencia (en un sentido o en otro) puede ser recurrida a la Sede Metropolitana (es decir, el arzobispado del que el obispado depende). Por lo que respecta a las Conferencias Episcopales, deberán ser sobre todo impulsoras del "ansia apostólica por llegar a los fieles dispersos", pero siempre respetando "el derecho de los Obispos de organizar la potestad judicial en la propia Iglesia particular". Finalmente, siempre queda el recurso a la Sede Apostólica [sic] (Roma).

La declarada intención es reducir el número de recursos. Lo cual evidencia el convencimiento de que un gran número de solicitudes serán resueltas afirmativamente por las respectivas diócesis. 
(...) El Papa es consciente de que esto puede enviar un mensaje equívoco a personas poco conocedoras de la doctrina de la Iglesia y llevarlas a pensar en una especie de "divorcio" católico.

Ante esto, es necesario decir que el matrimonio católico es indisoluble. "Nulidad" no es lo mismo que "anulación". Anular es dejar sin efecto. En cambio, declarar la nulidad del matrimonio es declarar que dicho matrimonio nunca existió. Lo que el obispo va a declarar no es que los miembros de la pareja "ya" no están casados... sino que nunca lo estuvieron, que es distinto (Navarro Girón, 2015).

\section{4. Álzate Monroy, A., precisa:}

Se considera que el actual proceso de nulidad matrimonial es demasiado largo, complicado y muy caro (en algunas ocasiones), lo que hace que muchos "fieles se alejen de las estructuras jurídicas de la Iglesia debido a la distancia física o moral". Para el Sumo Pontífice, "la caridad y la misericordia" requieren que la Iglesia como madre acerque a sus hijos que se consideran lejos de ella.

El Papa ha decidido retirar la apelación automática que se generaba luego de que se tomaba la decisión de nulidad, puesto que actualmente, una vez que se decide la nulidad de un matrimonio en primera instancia, éste debe pasar a un tribunal de segunda instancia, ya que se necesitan dos sentencias iguales, lo que puede ser una innecesaria postergación del proceso, particularmente cuando nadie contradice la primera sentencia. Sin contar que si no hay dos sentencias iguales, habría que ir a Roma para buscar la paridad de sentencias, con la consecuente demora, dificultad y carestía. Con esta reforma, solo se necesitará una sentencia, a menos que se haga una apelación. Si hay apelación, el Papa señala que ahora se podrá hacer en la Arquidiócesis más cercana, conocida como la "Sede Metropolitana" y ya no habrá necesidad de dirigirse a Roma.

El Pontífice también ha establecido que cada Diócesis en el mundo nombre a un juez o un tribunal de la Iglesia para procesar los casos. Cada Obispo local puede ser el único juez o puede establecer un tribunal de tres miembros. De ser así, al menos uno de ellos debe ser clérigo y los otros dos pueden ser laicos.

El Papa también ha declarado que el proceso de nulidad sea gratuito, una práctica que ya se realizaba en muchas Diócesis. La reforma hace que la gratuidad sea ahora universal (...).
El Papa también explicó que ha querido ofrecer este nuevo proceso a los Obispos para que "sea aplicado en casos en los que la nulidad matrimonial es particularmente evidente" como, por ejemplo, el aborto procurado para impedir la procreación, la obstinada permanencia en una relación extra conyugal durante el tiempo de las nupcias, el ocultamiento doloso de la esterilidad o de una grave enfermedad contagiosa o de hijos nacidos de una relación anterior o de una encarcelación (...).

Particularmente considero que esta reforma del Papa Francisco hará que muchos fieles católicos practicantes que se han casado por lo católico, se han divorciado y vuelto a casar por lo civil, y que se sienten alejados de la Iglesia por no poder comulgar -queriendo y deseando hacerlo- se animen a solicitar la posible y/o segura declaración de nulidad de su anterior matrimonio católico, pues antes no lo hacían por considerar lento, largo y costoso el proceso de nulidad. Es una sabia y acertada decisión del Sumo Pontífice, ya que no se está yendo contra el principio de la indisolubilidad del matrimonio, sino que se está afirmando que la Iglesia se preocupa por la "salvación de las almas" que es su principio y ley universal, facilitando que los católicos puedan acudir más fácilmente a su Iglesia para despejar "esa duda" de su posible nulidad matrimonial.

(...) Esta reforma animará a varios fieles a que su duda se despeje, aliviará sus conciencias y sentirán la cercanía y comprensión de sus Pastores, sin que ésto suponga declarar la nulidad en todos los casos, sino sólo cuando realmente exista alguna de las causales de nulidad matrimonial, las cuales siguen siendo las mismas (Álzate Monroy, 2015).

Si bien es cierto que la consulta, a nivel de los procesos en general, se justificaba por aquella "desconfianza” inicial respecto de algunos fallos o por aquel ánimo de protección y de garantía procesal de las partes, no debe olvidarse el principio de buena fe y las diferentes garantías procesales que la misma ley da a los procesos y en últimas a los fallos, por lo que la reforma del Papa Francisco además de so-lucionar un problema real de las causas matrimoniales, acoge la evolución dog-mática, legal y jurisprudencial en materia procesal que hace énfasis en la econo-mía y celeridad del proceso.

\subsection{Regulación y aplicación del Motu proprio}

En Colombia, a través del Decreto 913 del 8 de diciembre de 2015, expedido por el Cardenal 
Rubén Salazar, Arzobispo de Bogotá, se da aplicación al Motu pro-prio del Papa, en él se precisa que habrá "un mayor acompañamiento pastoral, rigor jurídico, celeridad y gratuidad", se precisa también que el Tribunal Eclesiásti-co Arquidiocesano contará además de su sala, con salas vicariales descentrali-zadas

Posteriormente el Tribunal Apostólico de la Rota Romana, del Vaticano, el 6 de enero de 2016, expidió el Subsidio aplicativo del Motu proprio, en el que se insis-te, entre otras cuestiones, en que los Procedimientos sean más simples y agiles.

\section{CONCLUSIONES}

Una de las características que acompañan al Papa Francisco es el mantener viva su preocupación - entre otras - por los problemas que los católicos tienen en el día a día relacionadas no solo con su fe, sino con los efectos que genera en su práctica cristiana las decisiones respecto del matrimonio católico.

Conforme a ello convocó en el 2014 y 2015 el Sínodo de Obispos para tratar el tema de la familia en el mundo, conjugar su preocupación por la unidad familiar, los problemas que atraviesa la institución de la familia y el matrimonio y dar así una respuesta a la realidad de las nulidades del sacramento del matrimonio. Co-mo consecuencia del Sínodo, el Papa Francisco promulgó la Exhortación Apostó-lica postsinodal "Amoris Laetitia" (Sobre el amor en la familia).

El Motu proprio del Papa ha sido de gran aceptación en los últimos días, por cuanto se propone agilizar el procedimiento de la nulidad del matrimonio católico, haciendo uso de la potestad eclesiástica de la cual dispone, como jefe de la cristiandad, la cual se materializó en el Motu proprio promulgado en el mes de septiembre del 2015 y que comenzó a regir a finales del 2015 con el inicio del año de La Misericordia.

En Colombia, existe un número significativo de católicos y un Concordato con la Santa Sede sobre el cual, aunque anterior a la Constitución del 91, la Corte Constitucional, ha venido reiterando su constitucionalidad en los diferentes pro-nunciamientos ante acciones públicas y tutelas de las que ha tenido conocimien-to. El reconocimiento que hace el Estado de la jurisdicción eclesiástica, se hace extensivo a los efectos civiles para quienes contraen matrimonio por el rito católico, o cuando se declara la nulidad de acuerdo con el Derecho Canónico. Sin em-bargo, en este punto cabe precisar que la ley 25 de 1992, que permite la cesación de efectos civiles de los matrimonios religiosos, está desconociendo en parte la potestad eclesiástica respecto de la disolución del vínculo sacramental, pues aún cuando el estado Colombiano aclara que solo está permitiendo la cesación de los efectos civiles, con ello también se permite un posterior matrimonio civil sin haberse anulado previamente el vínculo sacramental.

Como ya se expresó, la reforma promulgada por el Papa Francisco referente a que ya no se requiere el segundo grado de jurisdicción obligatoria, que confirme la primera sentencia de nulidad de un matrimonio católico, equivale a reconocer en la práctica el principio general de economía procesal, que garantiza tanto la celeridad en las causas matrimoniales y en parte la gratuidad ${ }^{49}$ que el principio comprende. También reconoció la legislación y jurisprudencia colombiana al momento de derogar o declarar inexequible la consulta en algunas áreas del derecho, tal como se desprende del estudio de la consulta en el derecho nacional.

A partir de ahora para los cónyuges que obtengan en primera instancia sentencia que declare existir la duda respecto de la validez del vínculo matrimonial, esta prestará mérito ejecutivo y por tanto las partes - por regla general - podrán acce-der a celebrar un posterior matrimonio católico. Pero si la sentencia de primera instancia niega la nulidad, se mantienen los cánones que regulan el recurso de apelación ante el Tribunal de Apelación, incluso se permite alegar una nueva causal que no se haya debatido ni probado anteriormente, aspecto este sustancialmente diferente del procedimiento del Estado en general, pues en derecho canónico se puede incluso cambiar la - causa petendi - en la apelación ${ }^{50}$.

Dado que el desconocimiento de la norma canónica conlleva la especulación noticiosa sobre el

49. Como abogada canonista que adelanta Nulidades matrimoniales ante los Tribunales Eclesiásticos, doy fe que dicha gratuidad - total - ya se aplica en Colombia, para las causas de los fieles que no cuentan con recursos para adelantar sus procesos.

50. Canon 1683 CIC: Si en el grado de apelación se aduce un nuevo capítulo por el que se pide la declaración de nulidad de un matrimonio, el tribunal de apelación puede admitirlo y juzgar acerca de él como en primera instancia. 
tema, con errores de apreciación, cabe reiterar que la normativi-dad sustantiva relativa a la disolución y a la nulidad del vínculo sacramental se mantiene.

Si bien el presente artículo no agota la explicación respectiva, a manera de preci-sión es pertinente resaltar que las causales de nulidad matrimonial por afectar la validez del vínculo se predican solo de hechos anteriores o concomitantes a la celebración del sacramento del matrimonio y, si la Iglesia se propone evangelizar en tal sentido, seguramente muchas parejas encontrarán que en su caso en par-ticular cabe intentar la nulidad del matrimonio. Esta además comprende más cau-sales que la nulidad del matrimonio civil, por comprender no solo lo relativo a la formalidad del acto y a la manifestación del consentimiento, sino también por los impedimentos propios de la legislación canónica.

La Nulidad se puede pedir incluso alegando causales dadas por ambos esposos, todo lo cual permite, a quien obtiene la nulidad del matrimonio, no solo contraer un "nuevo" matrimonio católico sino permanecer en comunión con la Iglesia.

\section{BIBLIOGRAFÍA}

- Adnés, P. (1969). El Matrimonio. Barcelona: Herder.

- Álzate Monroy, A. (13 de septiembre de 2015). AM Abogados. Obtenido de http:// www.am-abogados.com/blog/la-reformadel-proceso-de-nulidad-del-matrimoniocatolico/5810/

- BENEDICTO, XIV (1741) De la Constitución Apostólica Dei miseratione, 3 noviembre 1741, Obtenido de: http:// enchiridionfamiliae.com/z_componer. php?codigo $=0163$

- Bernáldez, A. (20 de 10 de 2015). GECOAS. Obtenido de GECOAS: http://www.gecoas. com/religion/historia/moderna/1535Mo.htm

- Bunge. ( 8 de septiembre de 2015). Official Vatican Network. Obtenido de News Vaticano: http://www.news.va/es/news/presentacionde-los-motu-proprio-del-santo-padre-2

- Cabreros de Anta, M. (1972). Reforma del proceso en las causas matrimoniales según lo Constitución Apostólica «Causas matrimoniales» de Pablo VI. Revista Ius Canonicum, Volumen XII, N II, Ed. Universidad de Navarra, 225-227.

- Cenalmor, D., \& Miras, J. (2004). El Derecho de la Iglesia, Colección de Textos Teológicos - Pastorales CELAM. Navarra: Ed. EUNSA.

- Cenalmor, D., \& Miras, J. (2010). El derecho de la iglesia. Curso básico de Derecho canónico. Pamplona: Universidad de Navarra.
- De Paolis, V. (2012). Los fundamentos del proceso matrimonial canónico según el Código de Derecho Canónico y la instrucción dignitas connubii. Anuario Argentino de Derecho Canónico , 2012, Vol. XVIII. Obtenido de http://bibliotecadigital. uca.edu.ar/repositorio/r

- Elgueta, M., \& Palma, E. (2010). La Investigación en Ciencias Sociales y Jurídicas. Santiago de Chile: Ediciones ORION Colección Juristas Chilenos.

- Francisco (2015). Vaticano II. CARTA APOSTÓLICA EN FORMA DE «MOTU PROPRIO», septiembre de 2015, Obtenido de: https://w2.vatican.va/content/ francesco/es/motu_proprio/documents/ papa-francesco-motu-proprio_20150815_ mitis-iudex-dominus-iesus.html

- Florez García, G. (1975). Estado e Iglesia en Colombia, Análisis: histórico-jurídico a los Concordatos de 1887 y 1973. Roma : Pontificia Universita'Lateranense.

- García Martín, J. (2010). Normas generales del Código de Derecho Canónico. EDICEP: Valencia.

- García Ochoa, L. (2011). La enseñanza del Derecho Canónico a partir de la estrategia didáctica del aprendizaje basado en problemas . Bogotá: Unversidad Javeriana.

- GASPARRI-SERÉDI. (1939). Constitución apostólica “Dei Miseratione”. Roma: C.I.C. Fontes.

- Gerosa, L. (1998). El Derecho de la Iglesia. 
Vol. XII. Valencia: EDICEP C.B. .

- Hernández, R., Collado, C., \& Baptista, P. (1992). Metodología de la Investigación. Ciudad de México: MCGRAW-HILL.

- Hervada, J. (2000 ). UNA CARO. Escritos sobre el matrimonio. Pamplona: Universidad de Navarra.

- Jaeger, H. (1960). Justinien et l’Episcopalis Audientia (Bibliografía sobre la episcopalis audientia). RHDFE(38), 214-262.

- LOA. (11 de 12 de 2015). LOA.ORG. Obtenido de http://www.loa.org.ar/espacioDetalle. aspx? ID = 0 f0 $9466 \mathrm{~d}-724 \mathrm{e}-44 \mathrm{~b} 6$ - aba 5dd834d25cabf.

- Lombardia, Pedro. (1975) Estructura del ordenamiento canónico., Pamplona. Ed.EUNSA.

- López Medina, A. (2010). El proceso de confirmación de sentencias declarativas de nulidad matrimonial en los tribunales eclesiásticos - Memoria para optar al grado de doctora. Huelva, Universidad de Huelva.

- Maldonado, J., \& Toro, F. d. (1975). El Derecho Canónico y el Derecho Civil. Pamplona: Ed. Eunsa.

- Navarro Girón, M. (9 de septiembre de 2015). ANULACIÓN DEL MATRIMONIO CATÓLICO. Motu proprio "Mitis Iudex Dominus Iesus". Ubiesdomine. Recuperado de [https:// ubiesdomine.Wordpress.com /2015/09/09/ motu-propio-mitis-iudex-dominusiesus-08-09-2015/: https://ubiesdomine. Wordpress.com /2015/09/09/motu-propiomitis-iudex-dominus-iesus-08-09-2015/

- Novoa Parra, M. E. (2008). Roma de la ciudad estado al Imperio. Bogotá: Grupo editorial educar.

- Pablo II, J. (1989). CODIGO DE DERECHO CANONICO. Pamplona, España: Ed. Eunsa, Universidad de Navarra.

- Pérez Tortosa, F. (2010). "Proceso y nulidad matrimonial canónica", Revista de la Facultad de Ciencias Sociales y Jurídicas de Elche Volumen I - Número 6 - Marzo de 2010 - págs. 145-189 ISNN: 1886-6611, Obtenido en: http://
revistasocialesyjuridicas.umh.es/Revista/ NUMERO_6_files/02-Perez.pdf

- Piero, C. (1953). La Crisis del Derecho. Traducción de Marcelo Cheret. Buenos Aires: Ediciones jurídicas Europa - América.

- Pinto, P. V. (2014). Observatore Romano. Obtenido de http://www.osservatoreromano. va/es/news/el-papa-francisco-reforma-elproceso-canonico-de-n\#sthash.SkzjZWER.dpuf

- Tamayo y Tamayo, M. (1997). El proceso de la investigación científica. Ciudad de México: LIMUSA S.A.

- Tirapu Martínez, D., \& López-Sidro, Á. (2004). Curso breve de derecho matrimonial canónico. Aspectos sustantivos y procesales. Granada: Comares.

- Viladrich, P. ( 1975). El Derecho Canónico. Pamplona : Ed. EUNSA.

\section{FUENTES JURISPRUDENCIALES}

- Corte Constitucional - Sentencia C-027 de 1993.

- - Carlos Gaviria Díaz

- - Marco Gerardo Monroy Cabra y otro.

- Clara Inés Vargas Hernández.

- --------- C-874 de 2003, M.P. Marco Gerardo Monroy Cabra

- ---oClara Inés Vargas Hernández

- ------- C-424 de 2015, M.P. Mauricio González Cuervo

- ---------- T-285 de 1994; M.P. Fabio Morón Díaz

- -------- T-200 de 1995; M.P. José Gregorio Hernández

- ------- T-946 de 1999. M.P. Antonio Barrera Carbonell

- ------- T-998 de 2002. M.P. Jaime Córdoba Triviño

- Corte Suprema de Justicia, 30 de Abril de 1987, M.P. Eduardo García Sarmiento 
